NBER WORKING PAPER SERIES

\title{
BENCHMARKING PORTFOLIO FLOWS
}

\author{
John D. Burger \\ Francis E. Warnock \\ Veronica Cacdac Warnock \\ Working Paper 24761 \\ http://www.nber.org/papers/w24761
NATIONAL BUREAU OF ECONOMIC RESEARCH
1050 Massachusetts Avenue
Cambridge, MA 02138
June 2018

The authors thank the IMF's Statistics Department for helping with bulk download access to the IMF's CPIS dataset; McKinsey Global Institute for data on total financial assets by country; Gian Maria Milesi-Ferretti and Philip Lane for providing early access to their External Wealth of Nations update; and Luis Catao and Zsoka Koczan for providing the inflation component of the IMF (2016) real policy rate variable. We are also indebted to Paolo Pesenti for many helpful suggestions, and thank for helpful comments Fabio Ghironi, Aart Kraay, Gian Maria MilesiFerretti, Alan Sutherland, Linda Tesar, Cedric Tille, two anonymous referees and participants at BIS-IDB Workshop "Cross-Border Flows in a New Economic Environment", BNM-IMF-IMFER Conference "Globalization in the Aftermath of the Crisis", Cass/ECB EMG Workshop on International Capital Flows, and seminars at Reserve Bank of New Zealand, South Africa Reserve Bank, and University of St. Andrews. The views expressed herein are those of the authors and do not necessarily reflect the views of the National Bureau of Economic Research.

NBER working papers are circulated for discussion and comment purposes. They have not been peer-reviewed or been subject to the review by the NBER Board of Directors that accompanies official NBER publications.

(C) 2018 by John D. Burger, Francis E. Warnock, and Veronica Cacdac Warnock. All rights reserved. Short sections of text, not to exceed two paragraphs, may be quoted without explicit permission provided that full credit, including $\odot$ notice, is given to the source. 
Benchmarking Portfolio Flows

John D. Burger, Francis E. Warnock, and Veronica Cacdac Warnock

NBER Working Paper No. 24761

June 2018

JEL No. F21,F3,G11

\begin{abstract}
$\underline{\text { ABSTRACT }}$
To gauge the amount of portfolio inflows a country can expect to receive, we create a benchmark, a longer-term baseline path around which actual flows fluctuate. The relationship between our benchmark and actual flows is quite strong for emerging market economies (EMEs). For our sample of 28 EMEs, there is a significant long-run relationship between actual portfolio flows and our benchmark, flows adjust strongly toward the benchmark, and our benchmark helps predict one-year-ahead changes in inflows. For advanced economies (AEs), results are less impressive, but again the benchmark performs well in directional forecasting exercises. In practical terms, it is informative to distinguish between movements toward the benchmark as opposed to movements away from the benchmark. An example: While portfolio inflows to both Asian EMEs and Latin America plummeted in 2015, our benchmark analysis correctly predicted that inflows should rebound in Asia (because flows had fallen far below the benchmark) but stay near the new, low level in Latin America (where the sharp decline in inflows was back to benchmark levels). We provide similar analysis for 45 countries, both advanced and emerging, for the 2000 to 2017 period.

John D. Burger

Loyola University Maryland

4501 N. Charles Street

Baltimore MD 21210-2699

jburger@loyola.edu

Francis E. Warnock

Darden Business School

University of Virginia

Charlottesville, VA 22906-6550

and NBER

warnockf@darden.virginia.edu

Veronica Cacdac Warnock

Darden Business School

University of Virginia

Box 6550

Charlottesville, VA 22906-6550

vwarnock@virginia.edu
\end{abstract}




\section{Introduction}

In late 2016 many wondered whether the 2015/16 slowdown in capital flows represented a post-crisis retreat from financial globalization or simply a temporary decline in cross-border flows. Globally, annual portfolio inflows averaged only US\$785 billion per year in 2015/16 (Table 1), well below the average of the preceding five years and even below the amounts during the Global Financial Crisis (GFC). For EMEs, 2015/16 inflows resembled the amounts received during the GFC and were sharply lower than in the 2010-14 period (Figures 1 and 2).

But how does one judge, in real time, if a slowdown in flows is abnormal (suggesting it might be temporary) or if the preceding period of elevated flows was abnormal (suggesting the slowdown is actually the "new normal")?

The analysis of international capital flows often compares flows in a recent period to flows in some past period. For example, the entire sudden stops and surges literature (see Calvo (1998) and Forbes and Warnock (2012) among many others) is built on a comparison of recent flows against historical levels. Milesi-Ferretti and Tille (2011), in documenting the Great Retrenchment of capital flows, compare a pre-crisis period with the collapse and recovery periods, while IMF (2016) focuses on the slowdown in flows during the 2010-15 period and the Lane and Milesi-Ferretti (2017) analysis of cross-border positions compares pre-crisis (2007) to their latest data point (2015). And both Bussière, Schmidt and Valla (2016) and McQuade and Schmitz (2016) compare a pre-crisis period with the more recent "new normal".

The existing literature is rich in insights, but leaves readers wondering what level of capital flows should be characterized as "normal". Bussière et al. (2016, page 16), for example, concludes that "it is hard to gauge if the pre-crisis properties and specificities of the various types of flows... will prevail in the 'new normal'....The changes that have taken place since the global 
financial crisis may correspond to a simple normalization, as suggested... by Coeuré (2015), after rather 'exuberant' times in the pre-crisis period."

Temporal comparisons of capital flows would be enhanced if there was a benchmark that in some sense defined "normal". Conceptually, there can be many possible benchmarks, and no obvious way to choose among them, but we would like our benchmark to be simple and intuitive while providing a time-series reference to pin down low-frequency "normal" movements around which actual flows will deviate. We prefer to stay clear of benchmarks that are purely statistical; we are not interested in a benchmark that is derived from a statistical trend, nor in one that is overly complicated and may perform well on the forecasting margin but is wholly unintuitive. Rather, we would like a benchmark that builds upon a fundamental framework or stylized narrative and enables some rationalization and explanation of why deviations from the benchmark are likely to be transitory. Ideally, deviations from our benchmark should help forecast the medium-term path of international capital flows.

An example of a benchmark in another strand of the international finance literature helps set the stage. Purchasing Power Parity (PPP) is an accepted benchmark for exchange rates, at least between advanced economies (AEs). PPP (and its building block, the law of one price) captures an intuitive long-term arbitrage in product markets and enables a narrative based on a potential mechanism of adjustment, rather than just an empirical trend. There is empirical evidence supporting reversion to PPP (although deviations have a sizable half-life). And PPP is not unique among exchange rate benchmarks; others include Balassa-Samuelson and FEER, and each "benchmark" will produce a specific quantification of an exchange rate gap or misalignment. Examples from the real side of the economy include benchmarks for economic activity (potential GDP), unemployment (natural rate or NAIRU), and interest rates (the natural rate of interest, $\mathrm{r}^{*}$ ). Each has origins in economic theory, each is an estimate subject to discussion and debate, and when 
considering their pros and cons it can be said that each serves as a benchmark to which measured data can be compared. PPP, potential GDP, NAIRU, and $r^{*}$ are worthy examples. What is an appropriate benchmark for capital flows?

In this paper we create a benchmark. Our measure of benchmark portfolio flows is intuitive: It is the amount of new money available for international capital flows (that is, rest-of-the-world savings) allocated according to past portfolio weights. Our benchmark is also consistent with theory; in particular, our benchmark is analogous to the Tille and van Wincoop (2010, henceforth TvW) "portfolio growth" component of capital flows in which new savings is invested at steady state portfolio shares. ${ }^{1}$ The $\mathrm{TvW}$ portfolio growth component maps into a long-run benchmark calculated as the amount of new funds available for investing-for portfolio investments, the amount of new funds available to commit to investments (whether domestic or foreign) is this year's new savings—allocated according to some pre-determined rule analogous to TvW's zero-order portfolio weights. We create benchmark portfolio inflows for a wide range of countries (17 AEs and 28 EMEs) for the 2000-2017 period. We focus on portfolio flows-bond flows, equity flows, and the sum of the two-because it is for portfolio flows that this notion of a benchmark is most appropriate. $^{2}$

Thus, the amount of new funds available to invest (whether at home or abroad) is given by the flow of new savings and benchmark flows are those new savings allocated using zero-order

\footnotetext{
${ }^{1}$ Kraay and Ventura $(2000,2003)$ first proposed “portfolio growth" flows in an analysis of current account balances (i.e., net capital flows). The Kraay and Ventura $(2000,2003)$ contributions to this literature are fundamental, but our benchmark is more closely related to Tille and van Wincoop (2010) and their focus on gross flows.

${ }^{2}$ Two things to note. One, while we have more than 17 AEs in our dataset, we collapse the Eurozone into one unit and so have only $17 \mathrm{AE}$ "countries". Two, we hope that future work might create benchmark flows for other components of international capital flows. For direct investment (DI), there is a natural analogy to our construction of benchmark portfolio flows; we provide some thoughts on this in the conclusion. For banking flows, it is less clear how to think about a benchmark (or even what BOP-based banking flows represent), but a step might be found in McCauley et al. (2017).
} 
portfolio weights. There are undoubtedly other plausible benchmarks. But, as we show graphically and empirically, our benchmark has many desirable features.

As a preview, we show actual flows and our benchmark for two regions (Figure A).

Benchmark flows should not be mistaken as trend lines, as they are derived from investor countries' macroeconomic conditions. They do appear to be a "natural line" or long-run anchor around which actual flows oscillate. And what is apparent in the figure is also evident in empirical analysis, as we will show that inflows_-especially EME portfolio inflows_-adjust to the benchmark both in sample (as shown in error correction models) and out of sample (in year-by-year directional forecasts and in model-based forecasts of recent flows).

Figure A. Benchmark and Actual Portfolio Inflows for EME Asia and Latin America (annual, in billions of US\$)

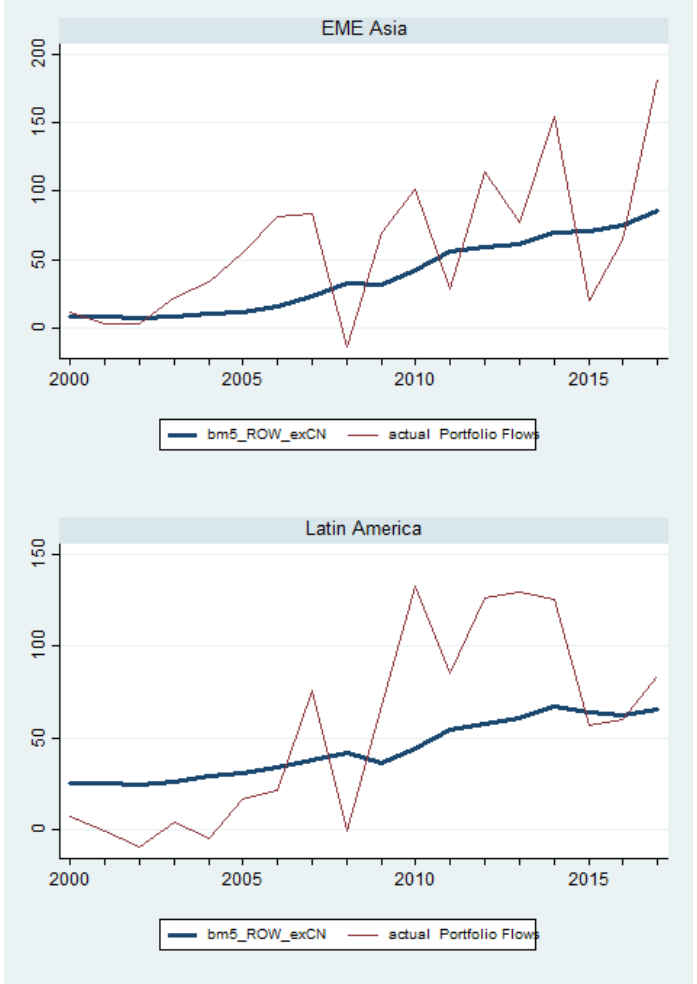

Having a benchmark provides context when investigating sharp movements in capital flows. For example, EME Asia’s portfolio inflows plummeted from US\$155 billion in 2014 to US\$20 billion in 2015 (Figure A). Was the sharp decline in inflows surprising? Without a benchmark, one 
can only state (and analyze) the extent of the slowdown compared with some previous period. But Figure A reveals that the slowdown pushed EME Asia's portfolio inflows below our benchmark, suggesting that the 2015 slowdown would likely be reversed (which indeed occurred in 2016/17). In contrast, the sharp 2015 decline in Latin America's portfolio inflows was a return to benchmark levels, so our analysis suggests that 2016 and 2017 flows should be similar to those in 2015, which they were. The recent dynamics of portfolio inflows into Latin America and EME Asia highlight an important feature of our analysis: Having a benchmark enables the differentiation of sharp movements away from benchmark levels from sharp movements toward the benchmark. The former (movements away from the benchmark) are likely temporary, whereas the latter (movements toward the benchmark) are likely to be sustained.

The paper proceeds as follows. Section 2 discusses how we create benchmark flows, Section 3 compares actual and benchmark inflows through a series of graphs and descriptive analysis, Section 4 presents statistical evidence on both the long-run relationship between actual and benchmark inflows as well as the benchmark's value in out-of-sample forecasting exercises, Section 5 presents some illustrative regressions of country-level deviations from the benchmark (i.e., the difference between actual flows and benchmark flows), and Section 6 concludes.

\section{Forming Benchmark Portfolio Flows}

\subsection{The Framework}

In our opinion a benchmark should have the following features:

- It should be simple and intuitive while providing a time-series reference to pin down lowfrequency "normal" movements around which actual flows will deviate. 
- It should build upon a fundamental framework or stylized narrative that enables some rationalization and explanation of why deviations from the benchmark are likely to be transitory.

- Ideally, deviations from the benchmark should help forecast the medium-term path of flows.

The first two desirable characteristics push us toward a benchmark that is at least roughly consistent with the Tille and van Wincoop (2010, TvW) notion of portfolio growth flows. TvW develop a twocountry dynamic stochastic general equilibrium (DSGE) model in which gross capital flows are endogenous. For our purposes, an important feature of the TvW model is the notion of portfolio growth flows: "The portfolio growth component captures capital flows that result when saving is invested in line with the zero-order portfolio shares." 3

This notion is intuitively appealing, as the flow of new savings is precisely the amount of new funds available for foreign (or home) investment. Portfolio growth flows are simply the gross flows that would occur if those new funds are allocated according to zero-order portfolio weights. Other flows occur. In the language of $\mathrm{TvW}$, actual gross flows are the sum of zero-order, first-order and second-order flows. The zero-order flows, essentially the flows that would occur absent any shock to expected returns and risk, are our benchmark. Shocks occur-in TvW first- and second-order portfolio weights (and, hence, the related flows) are reallocations due to shocks in expected returns and risk-and thus actual flows deviate from benchmark flows. But a plausible benchmark is one in which new funds are allocated according to zero-order portfolio weights.

\footnotetext{
${ }^{3}$ The quote is from page 163 of TvW. Two things to note. One, the portfolio allocation model of Devereux and Sutherland (2011) has a similar zero-order steady-state notion. Two, the model in TvW is a two-country model and hence says nothing directly about allocations across foreign markets, so our benchmark concept can best be described as "in line with" TvW. Finally, see also Ahmed et al (2018) for a practical application that decomposes gross portfolio outflows using the insights of TvW.
} 
Specifically, let countries be denoted by $o$ (origin) and $d$ (destination). Denote the period $t$ zero-order weight of destination country $d$ in origin country o's portfolio as $\omega_{o d, t}$. Benchmark gross capital flows from $o$ to $d$ in period $t$, which we denote by $G C F_{o d, t}^{b m a r k} \_p g$ (where $p g$ indicates that the benchmark is analogous to the TvW notion of "portfolio growth" flows), are the new savings generated in $o$ in the current period $\left(S_{o, t}\right)$ allocated according to its zero-order portfolio weights $\left(\omega_{o d, t}\right)$. That is,

$$
G C F_{o d, t}^{\text {bmark } \_p g}=\omega_{o d, t} S_{o, t}
$$

Summing across all $O$ origin countries provides destination country $d$ s total benchmark inflows.

$$
G C F_{d, t}^{b m a r k} p g=\sum_{o=1}^{o=0} \omega_{o d, t} S_{o, t} \quad(\text { for ofd })
$$

In (1) and (2) $\omega_{o d, t}$, the bilateral portfolio weight between $o$ and $d$ (specifically, the weight of $d$ in $o$ 's portfolio), can be formed using holdings data from the IMF's CPIS dataset, which reports the bilateral portfolio (bond and equity) holdings of about 60-80 origin countries starting in 2001 .

Another way of forming country $d$ s s total benchmark inflows is to use aggregate ROW ("rest of the world") data, where the weights are $\omega_{R O W, d, t}$ or the weight of destination country $d$ in ROW portfolios:

$$
G C F_{d, t}^{\text {bmark_pg }}=\omega_{R O W, d, t} S_{R O W, t}
$$


Portfolio weights in (3) can be formed using Lane and Milesi-Ferretti (2017) data on the stock of portfolio equity and portfolio debt liabilities, available annually for a wide range of countries starting in roughly $1995 .^{4}$

Portfolio weights, whether using the bilateral approach (eq. 2) or the ROW approach (eq. 3), also require data on savings and a scale factor for portfolios. For origin countries' savings (in billions of US\$) we use data in IMF WEO; specifically, we multiply national savings rates by country-level data on GDP in billions of current US\$. To scale origin countries' portfolios, we take a broad view and consider each country's stock of total financial assets (TFA), which is available from McKinsey Global Institute (MGI). ${ }^{5}$ Specifically, to create the size of a country's portfolio, we add its net foreign assets to its TFA, effectively subtracting out foreigners' claims on the country's TFA and adding the country's claims on other countries' TFA. For the ROW version of our benchmark, we simply subtract the destination country from global TFA and global savings. For example, the ROW weight on Thailand's equities equals the stock of Thailand's portfolio equity liabilities (that is, ROW holdings of Thai equities) divided by ROW total financial assets (global financial assets less the sum of Thai financial assets and Thai net foreign assets).

\subsection{The Details: Practical Choices when Forming a Benchmark}

Equations (2) and (3) look simple enough but have a number of practical challenges that we discuss in this subsection: how to create zero-order portfolio weights and whether to use the bilateral or ROW approach (which in turn raises a question about how to deal with China).

\footnotetext{
${ }^{4}$ The Lane and Milesi-Ferretti (2017) data start earlier than 1995, but prior to 1995 there is dramatically reduced country coverage.

${ }^{5}$ Pulling primarily from publicly available sources, MGI calculates for a wide range of countries total financial assets as the sum of a country's equities, bonds and loans.
} 


\subsubsection{Zero-order Porffolio Weights}

What exactly are the zero-order portfolio weights as of time $t$ ? In Devereux and Sutherland (2011, pg. 350), zero-order portfolio holdings are "the equilibrium for portfolio holdings in a world with an arbitrarily small amount of stochastic noise". Similarly, in TvW the zero-order component is the value when the volatility of shocks becomes arbitrarily small.

We want our benchmark to be useful in real time-it should provide information on the amount of flows a destination country $d$ should expect to receive this year-and we are also constrained by data (as described below, we only have about two decades of annual data). Given those considerations, a 5-year lagged moving average of portfolio weights seems in line with the TvW and Devereux and Sutherland (2011) notion of zero-order weights.

In Figure B we illustrate, using the ROW approach, benchmarks a 5-year lagged moving average of portfolio weights and two other weighting schemes: a simple one-period lagged weight and a 3-year lagged moving average. The simple one-period lagged weight produces the most volatile benchmark (the most volatile thin solid lines in Fig. B), but all three weighting schemes produce broadly similar benchmark flows. We choose to calculate zero-order flows using a trailing 5-year average of portfolio weights.

Figure B. Benchmarks using 1-, 3-, and 5-year lagged weights
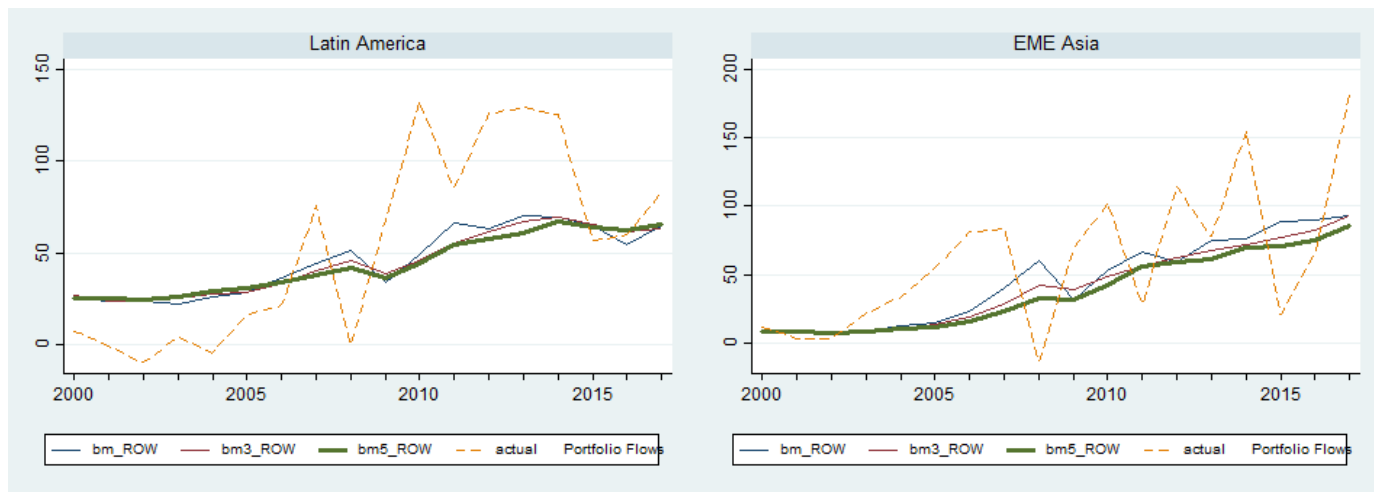


\subsubsection{ROW or Bilateral Approach}

The above is straightforward enough: Define zero-order portfolio weights and apply them to savings. Different researchers might make slightly different choices on those aspects when creating their own preferred benchmark, but the resulting benchmarks will likely be quite similar.

The next decision is a bit more substantive: whether to use the ROW or bilateral approach. There are pros and cons associated with both approaches. A strength of the bilateral approach is that it attributes savings to origin countries according to each country's exposure to the destination country, which can be important if origin countries' weights differ substantially for a particular destination country. Weaknesses of the bilateral approach are that CPIS data exclude official holdings (important for a reserve currency country like the US, but not for EMEs), have a geographic bias due to the use of international financial centers, and do not include all of the world's origin countries. The omissions in the CPIS data are, in aggregate, substantial; as of end-2015 world cross-border portfolio liabilities were $\$ 13.8$ trillion greater in the LMF (2017) dataset than in the CPIS data (Table A).

Table A. Cross-border Portfolio Liabilities (end-2015, trillions of USD)

$\begin{array}{lcc} & \text { LMF } & \text { CPIS } \\ \text { Portfolio Equity Liabilities } & 27.0 & 22.5 \\ \text { Portfolio Debt Liabilities } & 32.2 & 22.9 \\ \text { Total } & 59.2 & 45.4 \\ & & \\ \text { memo: World Reserves } & 11.4 & \end{array}$

Much of difference is due to reserves, which as noted are excluded from the CPIS; the rest must be due to the omission of some origin countries. Thus, one strength of the ROW approach is that it doesn't rely on bilateral data (which isn't complete). In addition, the ROW approach is consistent with BOP capital flows data (which are also ROW). In practice, the ROW approach (equation 3) 
creates larger benchmark flows; see Figure C for EME Asia and Latin America. Note that for EMEs the much lower CPIS-based benchmark cannot be due to the exclusion of reserves in the CPIS as these countries do not typically receive reserve flows. Perhaps the low CPIS-based series is because some source countries are not included in the CPIS dataset. Whatever the reason, after considering the pros and cons of both approaches, we employ the ROW (LMF) approach and use equation (3) to create benchmark flows. ${ }^{6}$

Figure C. Bilateral (from CPIS) and ROW (from LMF) Benchmark Flows to EME Asia and Latin America ${ }^{7}$
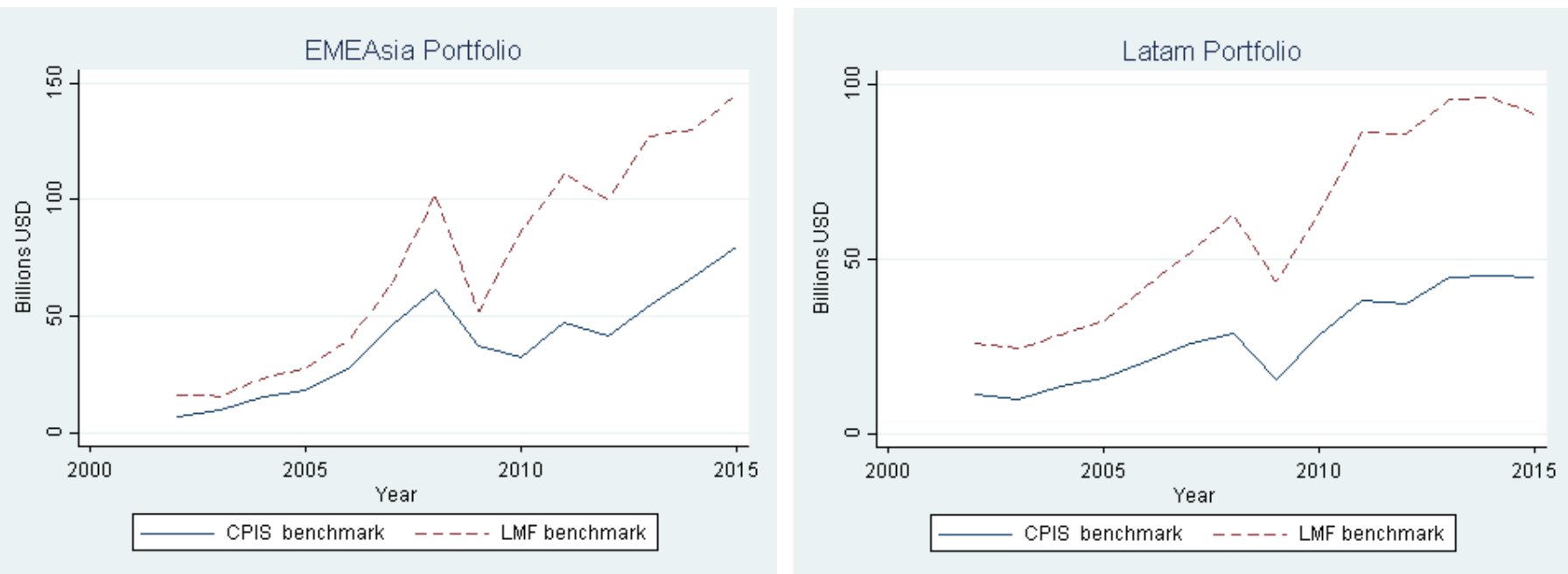

\subsubsection{The ROW Approach and China as a Source Country}

Once the decision to use the ROW approach is made, China as a source country presents an additional complication. The ROW approach assumes that all ROW savings are allocated in the same way—specifically, according to ROW portfolio weights. One particular country for which this

\footnotetext{
${ }^{6}$ For the Eurozone, to avoid double counting of within-union flows, we use Eurozone aggregates rather than individual countries.

${ }^{7}$ Note that in Figure C, for an apples-to-apples comparison and so we can start the figure in 2002 (the year after the first broad CPIS dataset), we use a single lag of portfolio weights to form benchmark flows.
} 
simplification can be problematic is China, which creates a large portion of world savings $(27 \%$ in 2015) while having comparatively little outbound international portfolio investment. As of end-2015, according to LMF (2017) data, China's portfolio equity assets and portfolio debt assets were each less than $1 \%$ of the global aggregates. And even if one adds its $\$ 3$ trillion in reserves to its stock of portfolio debt assets, China's bond holdings are still only $10 \%$ of the global aggregate, quite small for a country that generates a quarter of global savings.

To adjust for the disconnect between the importance of China in world savings and its (limited) propensity to invest internationally we proceed in three steps:

- Construct an "exChina" benchmark that excludes China from ROW savings, which greatly reduces the amount of ROW funds available for cross-border investment.

- Adjust flows for comparability of flows and the benchmark. Because China's reserve flows are included in recipient countries' inbound portfolio flows BOP data, we also need to reduce destination country actual bond inflows by an amount implied by China's overall reserve flows and COFER (Currency Composition of Official Foreign Exchange Reserves) reserve currency weights. ${ }^{8}$ This portion of our China adjustment affects only seven 'reserve currency' countries_-US, UK, Switzerland, euro area, Japan, Australia and Canada - and in most years subtracts annual flows ranging from to $\$ 11$ billion in 2000 (across the entire group) to $\$ 480$ billion in 2008 . In 2015 and 2016, when China's reserves declined, this adjustment adds (across the group of seven) $\$ 343$ billion and $\$ 444$ billion, respectively.

\footnotetext{
${ }^{8}$ That is, we allocate China's reserve flows according to the weight of reserve currencies in overall "allocated" reserves; see the IMF's COFER site for details. In addition, we assume the reserve flows are into bonds, although some (presumably small) portion is also in equities, and we are identifying "country" with "currency", although clearly China could (for example) purchase USD-denominated bonds issued by entities in other countries.
} 
- Adjust ROW portfolio weights. For the seven reserve currency countries, we must reduce the ROW's weight on their bonds by China's implied bilateral official holdings.

The above three points constitute our "exChina" adjustment to benchmark and actual flows. For all countries, removing China from ROW savings will reduce benchmark inflows. For reserve currency countries, further adjustments are made to both benchmark and actual bond flows; actual bond flows are reduced every year except 2015 and 2016.

Figure D shows benchmark and actual bond flows for the US, the country most affected by China's flows, using “exChina” series and raw series. With the exChina adjustment (Fig. D, left graph), benchmark flows are less (because China's savings are omitted and ROW's weight on US bonds are reduced) and actual flows are usually less (as we omit China's implied reserve flows to the US). For other countries the China adjustment is less pronounced.

Figure D. Benchmark and Actual Bond Flows to the US: With and Without a China Adjustment

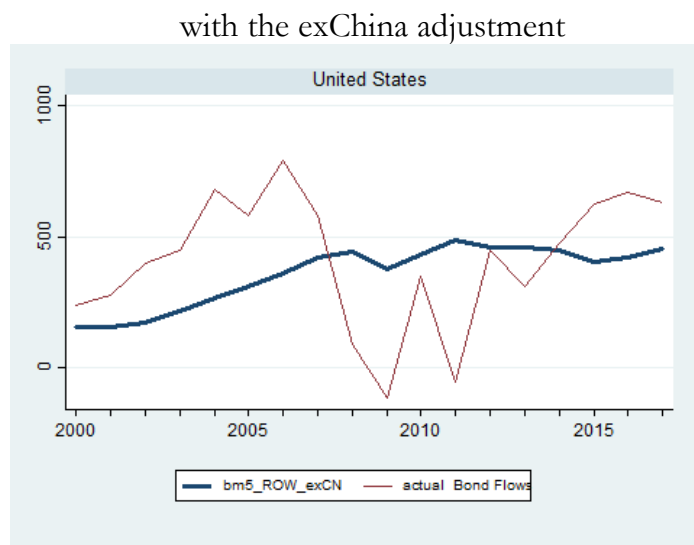
without the exChina adjustment

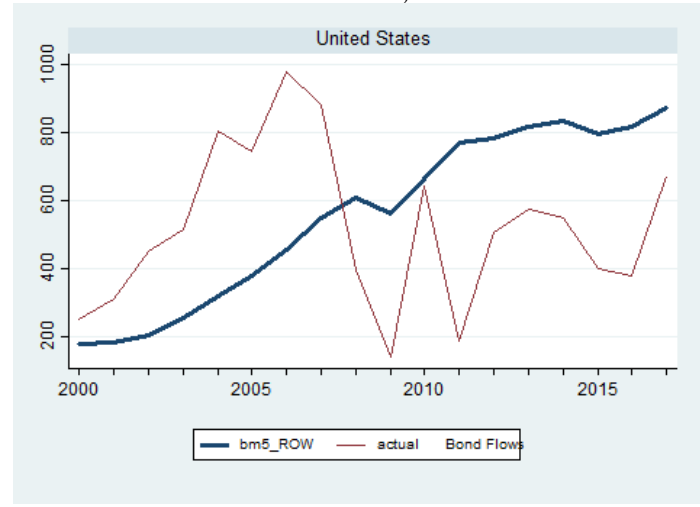

Our China adjustment seems the best that can be done given limited information on China's bilateral official and private holdings, but is not perfect in that on a bilateral basis we can only 
compute implied China official flows and positions and we cannot remove private China flows from recipient countries' BOP flows and, hence, our actual flows. ${ }^{9}$ All things considered, our baseline benchmark will use the exChina adjustment. ${ }^{10}$

\subsection{The Benchmark: Connection to Global GDP and a Decomposition}

We note that regardless of practical choices that must be made when forming a benchmark, our benchmark flows are directly connected to ROW economic conditions, arising (by construction) from the flow of new ROW savings. The amount of new savings is of course closely related to income-savings rates can vary year to year, but to a first approximation the level of savings is driven by the level of income-so savings is highly correlated with GDP whether in levels (both are flow concepts) or first differences (Figure 3). Thus, benchmark portfolio inflows for each country will be closely related to ROW GDP, providing a baseline path that is connected to ROW macroeconomic conditions.

A reasonable question is which component—changes in ROW portfolio weights or the evolution of new ROW savings-drives changes in our benchmark. The answer, shown in the last graph of Figure 3, is both. From 2000 to 2017, benchmark inflows, summed across all countries in our sample, increased by $\$ 2726$ billion from $\$ 790$ billion to $\$ 3516$ billion. Fixing portfolio weights at 2000 levels (actually, the average of 1995-1999, as our benchmark uses a 5-year trailing average) allows us to compute the amount of that increase that comes from the evolution of ROW savings

\footnotetext{
${ }^{9}$ China started reporting to the CPIS dataset in 2015, so there is no obvious way to strip out China's private portfolio flows back to 2000. We do not believe the inability to exclude China's private flows impacts our analysis much, as the entire stock of China's outbound private portfolio investment - the type of positions picked up by the CPIS-amounted to only \$261 billion as of 2015, with much of that being invested in the US, Europe and Japan. Compared to its over \$3 trillion in official reserves, China's reported private portfolio holdings are quite small.

${ }^{10}$ As we note in the conclusion, while the adjustment certainly affects analysis of flows into at least one country (the US), none of our empirical results (presented in Sections 4 and 5) is materially affected by the exChina adjustment; that is, the discussion of our empirical results does not hinge on using data with the exChina adjustment as opposed to raw unadjusted data.
} 
(depicted as the "fixed weight" dashed line in the last panel of Fig. 3). The "fixed weight" benchmark increased $\$ 1181$ billion over the 2000-2017 period, meaning that increased ROW portfolio weights (from $10.6 \%$ in 2000 to $18.8 \%$ in 2017, which is one manifestation of the erosion of the long-standing home bias) accounted for $\$ 1545$ billion (or 57\%) of the increase. Both increased ROW portfolio weights and increased global savings have increased our benchmark flows.

\section{Comparing Actual and Benchmark Portfolio Flows}

Figure 4 shows, for total portfolio (i.e., bond and equity combined) and, separately, for equity and bond flows, actual (the thin line) inflows and benchmark inflows (the thicker line). Benchmarks are based on a 5-year lagged moving average of portfolio weights and for both actual and benchmark we use the "exChina" adjustment. Graphs are presented for EME Asia, Latin America, US, Eurozone, EME Other and AE Other (see Table 1 for the composition of groups) for the period from 2000 to 2017.

The various graphs in Figure 4 indicate a few regularities of benchmark inflows. One, they are positive; for benchmark flows to any country to be negative, annual ROW savings would have to be negative. Two, while benchmark portfolio inflows declined during the global financial crisis (because ROW savings fell), over time they tend to increase; absent a surge in home bias, an expanding global economy and increasing global savings increase benchmark flows.

\section{EME Asia}

Actual portfolio flows to EME Asia were running higher than the benchmark in the years prior to the GFC - the thin line (actual flows) line in Figure 4 was above the thick line (benchmark flows) line through 2007—consistent with the elevated number of sudden surges (Forbes and Warnock 2012) during that period. Actual portfolio flows to EME Asia decreased sharply during the 
GFC, the Great Retrenchment documented in Milesi-Ferretti and Tille (2011). Following the GFC portfolio inflows were again elevated, until they fell sharply in 2015 to below-benchmark levels. If

our benchmark is a reasonable long-run measure, we would expect portfolio inflows to EME Asia to rebound from the very low 2015 levels, and in subsequent years they have.

Turning to the components, we note that EME Asia's bond inflows have been elevated almost every year since 2003, with the only exceptions being during the GFC and in the 2015 slowdown. The 2015 slowdown in EME Asia's bond inflows was a return to benchmark following much higher than benchmark inflows during the 2010 to 2014 period; here we would have expected EME Asia bond inflows to remain near the 2015 levels, but in the event they increased sharply (due to large inflows into Chinese and Indonesian bonds). In sharp contrast are EME Asia's equity inflows which, while elevated pre-GFC, then oscillated around the benchmark before falling sharply to below benchmark levels in 2015 .

In sum, the 2015 sharp slowdown in EME Asia portfolio inflows appears to have been a temporary deviation from longer-term benchmark levels, largely because equity inflows fell far below the benchmark, and thus our analysis suggests inflows should rebound. Flows did rebound somewhat in 2016 and dramatically in 2017 due to a surge in bond inflows. Going forward, based on our benchmark analysis, we expect equity flows into EME Asia to increase, bond inflows to decrease, and overall portfolio inflows to decrease.

\section{Latin America}

Latin American portfolio inflows fell sharply in 2015/16, but for this region we expect inflows to remain near current levels as recent Latin American portfolio inflows are in line with the benchmark. The decline in Latin American inflows is solely due to a sharp drop in bond inflows from the elevated level of 2010-14 to near benchmark levels, while equity inflows are slightly below 
benchmark. Overall, with actual flows close to benchmark levels, we expect LatAm inflows to remain near current levels.

\section{US and Eurozone}

Since the beginning of the Eurozone debt crisis and QE programs, inflows in both the US and Eurozone have tended to stay below benchmark levels. For the Eurozone, the low level of inflows is due to bond flows_-Eurozone bond inflows were negative US\$200 billion in 2017 when the benchmark suggested US $\$ 200$ billion in inflows-while equity inflows have recently rebounded. For the US, bond inflows were quite low starting in the GFC and rebounded in 2012, whereas equity inflows stayed near benchmark levels following the crisis but then fell substantially in 2013. Overall, in 2017 the US received the benchmark amount of portfolio inflows, so while we expect bond inflows to decrease and equity inflows to increase, the overall level of US portfolio inflows seems to be a return to normal.

\section{Other EMEs and Other AEs}

Both of our "other" groups, which contain a number of important countries not elsewhere classified, are experiencing near benchmark portfolio inflows, with below benchmark equity inflows roughly offsetting above benchmark bond inflows. As such, we expect overall portfolio inflows to both sets of countries to maintain current levels with equity inflows increasing and bond inflows decreasing. More details on selected countries are provided next.

\section{Selected Individual Countries}

Country groupings can mask heterogeneity across countries, so in the appendix we present benchmark and actual flows for selected countries (grouped by regions). Some countries (Australia, 
UK, Mexico, and Poland) are at about benchmark levels for portfolio inflows and both components (bonds and equities). Countries below benchmark for portfolio inflows and both components include Brazil and Philippines, while countries at or above all their benchmarks are Canada, Argentina, China, South Africa and Turkey. Some countries (India, Indonesia, Thailand) are currently receiving large bond inflows that more than offset decreased equity inflows (and hence, in sum, they are receiving sizeable portfolio inflows). Finally, Japan and Russia are currently receiving benchmark-level portfolio inflows as strong bond inflows offset weaker equity inflows, while portfolio inflows into South Korea and New Zealand are below benchmark levels.

\section{Empirical Evidence on the Relationship between Actual and Benchmark Portfolio Flows}

The descriptive comparison of actual and benchmark flows provided in Section 3 suggests that benchmark flows can be thought of as a longer-term baseline path around which actual flows fluctuate. In this section we empirically evaluate the benchmark in two ways. First, we provide formal tests of our benchmark's long-run relationship with actual portfolio flows by conducting panel cointegration tests and estimating error correction models (with particular interest in their long-run coefficients and speed of adjustment parameters). Second, we assess the benchmark's performance in generating two types of out-of-sample forecasts, one model based (based on the error correction model) and another directional.

\subsection{Long-run Relationship between Actual and Benchmark Portfolio Flows}

Analogous to the PPP literature, we begin by evaluating whether actual and benchmark flows are cointegrated. Table 2 provides results from two panel cointegration tests: Kao (1999) tests that assume a common cointegrating vector and AR parameter across panels (top panel) and Pedroni $(1999,2004)$ tests that allow for panel specific cointegrating vectors and AR parameters 
(bottom panel). Each test has a null hypothesis of no cointegration, and we include panel fixed effects while demeaning across panels to control for cross-sectional dependence. These tests have relatively low power for samples of our size (in particular the limited time dimension) but provide a useful starting point to evaluate the proposed benchmark.

The Kao and Pedroni panel cointegration tests each provide evidence that total portfolio flows are cointegrated with the benchmark. Splitting by asset class provides mixed results as the Kao tests provide stronger evidence of cointegration for bond flows, while Pedroni tests suggest equity rather than bond flows are cointegrated with the benchmark. Looking at the AE/EME splits, the Pedroni tests provide stronger evidence of cointegration for the EME sub-sample.

While Table 2 results provide evidence that there is a long-run equilibrium relationship between actual and benchmark portfolio flows, one could argue that cointegration is a necessary but not a sufficient condition for a suitable benchmark. More compelling evidence requires the use of error correction models to estimate the long-run relationship and the degree to which actual flows revert to the benchmark. Given the cointegration results in Table 2-in particular, the mixed results for the components but strong results for total portfolio flows-we focus on total portfolio flows and estimate pooled mean group models of the form:

$$
\Delta \text { flows }_{i t}=\alpha_{i}+\beta_{i} \text { bmark }_{i t}+\lambda_{i}\left(\text { flows }_{i, t-1}-\theta \text { bmark }_{i, t-1}\right)+\mu_{i t}
$$

The pooled mean group estimator of Pesaran, Shin, and Smith (1999) constrains the long-run coefficient $\theta$ to be constant across panels but allows for country-specific error correction terms $\left(\lambda_{\mathrm{i}}\right)$. Table 3 provides estimates for the long-run coefficient $\theta$ on benchmark portfolio flows where the coefficient on actual portfolio flows has been normalized to 1 (as in equation 4). A strong form test 
of the benchmark, analogous to absolute PPP, would require $\theta=1$ and imply stationarity of the absolute difference between actual and benchmark flows.

The strongest evidence in Table 3 is for EMEs, which perhaps is to be expected given the visual descriptive evidence and statistical cointegration tests. For the EME sub-sample (column 3), we estimate $\theta=0.976$, and a chi-square test fails to reject the null of $\theta=1$, providing strong evidence of a long-run relationship between the benchmark and actual portfolio flows. The speed of adjustment parameter is negative and highly significant $(\lambda=-0.751)$, suggesting that portfolio flows rapidly revert toward the benchmark. ${ }^{11}$ The error correction coefficient reported in column (3), suggests, for example, that an EME experiencing portfolio inflows that exceed benchmark flows by $\$ 10$ billion should expect, ceteris paribus, a decline in flows of $\$ 7.51$ billion in the following year. To gauge whether the benchmark adjusts to flows, in column (4) we re-estimate the error correction model for the EME sub-sample but with the change in benchmark flows as the dependent variable. The positive and significant coefficient on the error correction term $(\lambda=0.034)$ indicates that the benchmark responds positively to close the gap with actual flows, but the size of the coefficient is much smaller than in column (3), suggesting that the bulk of the adjustment is actual flows moving toward the benchmark.

Results for the full sample (column 1) and the AE sub-sample (column 2) are weaker. For the full sample, we estimate $\theta=0.283$ and strongly reject a null hypothesis of $\theta=1$. In the AE subsample (column 2) $\theta$ is insignificantly different from zero. Error correction terms are still large, negative and statistically significant, but the fact that $\theta$ is quite small (full sample) or insignificantly different from zero (AE sample) calls into question the error correction model for these samples. In contrast, for the EME sub-sample we find strong evidence of a significant long-term relationship

\footnotetext{
${ }^{11}$ In Table 3, for ease of presentation we report the cross-panel average of $\lambda_{\mathrm{i}}$. The panel specific estimates for $\lambda$ is negative and statistically significant (at the $5 \%$ level) for 22 of the 28 EMEs in our sample.
} 
between flows and our benchmark. In particular, for EMEs portfolio flows adjust to close the previous period's gap between flows and the benchmark.

\subsection{Using the Benchmark to Forecast Portfolio Flows}

In the descriptive comparison of actual and benchmark flows conducted in Section 3, we suggest that the deviation between actual flows and the benchmark helps predict future flows. In Section 4.1 we provide econometric evidence for that predictive power in the EME sample, based on a statistically and economically significant cointegrating relationship between our benchmark and actual portfolio flows. A natural next step is to test the out-of-sample forecasting ability of the benchmark. We do this in two ways. First, we create model-based out-of-sample forecasts by estimating the error correction model through 2014 and then forecasting flows for 2015, 2016 and 2017. Second, we evaluate the benchmark's performance in a directional forecasting exercise; that is, we test if the benchmark by itself is valuable in predicting whether inflows in the subsequent year will increase or decrease.

\subsubsection{Model-based Out-of-Sample Forecasts for EME Portfolio Flows}

Our short sample of just 18 annual data points hinders our ability to evaluate model-based out-of-sample forecasts. But we do so. Specifically, we re-estimate the pooled mean group error correction model from column (3) of Table 3 using part of the sample (2000-2014) to capture the average speed of adjustment parameter $(\lambda)$ and then apply that estimated $\lambda$ to predict flows for the

remaining years of data $(2015,2016$, and 2017). Although the out-of-sample portion of this exercise is quite limited, it does include the 2015-2016 slowdown and the 2017 bounce back, periods that might be considered difficult to predict.

We calculate the one-period-ahead forecast for the change in portfolio flows as follows: 


$$
\Delta \text { flows }_{i, t}^{e}=-0.694\left(\text { flows }_{i, t-1}-\text { bmark }_{i, t-1}\right)
$$

where $\lambda=-0.694$ is from the model in Table 3 (column 3) estimated over the 2000-2014 period. Note that (5) is not truly out of sample as we use the actual lagged deviation of flows from the benchmark; that is, to predict 2016 flows we use the 2015 deviation of flows from the benchmark (times the adjustment parameter).

Figure 5 a presents a scatterplot of the actual v. predicted change in portfolio flows for EMEs during the years 2015, 2016 and 2017 (that is, 3 years for 28 EMEs or 84 observations in all). The scatter plot reveals an impressive performance of the error correction forecasting model; the correlation between actual and forecasted change in flows is 0.57 and most (59 of 84 ) observations lie in the first and third quadrants (in which the forecasted and actual changes have the same sign). We also do the same exercise for 2017 using $\lambda=-0.744$, the estimate using data from 2000 to 2016. While the fit is less impressive (Figure 5b, correlation between actual and forecast is 0.13 ) because of two outliers in the fourth quadrant - the model predicted that portfolio inflows received by both China and Argentina would decrease in 2017 but they did not - in 20 of the 28 cases the modelbased forecast got the sign correct.

\subsubsection{Directional Forecasts}

In many cases directional forecasts — forecasts of the direction of a change in an economic variable — can add considerable value, regardless of the statistical precision of the forecast. For example, Leitch and Tanner (1991) argue that the value of forecasts to firms hinges on whether they can increase profits, not whether the forecast's root-mean-squared error is small. Similarly, Merton (1981) notes that for evaluating market-timing performance, what matters is if the forecast correctly predicts which will outperform, stocks or bonds, rather than the magnitude of the outperformance. 
Schnader and Stekler (1990) extend Merton (1981) to assess the value of forecasts of whether economic growth will slow or accelerate. In our context policy makers and market participants might value the ability to forecast whether portfolio flows received by a particular country are likely to increase or decrease from current levels.

We next evaluate our benchmark's performance in a directional forecasting exercise. We can construct a simple benchmark-based forecast of the direction of the change in portfolio flows by assuming that flows will adjust toward the benchmark. Specifically, the benchmark-based forecast of next period's change in flows is given by:

$$
\Delta \text { flows }_{i, t}{ }_{i, t}=-\left(\text { flows }_{i, t-1}-\text { bmark }_{i, t-1}\right)
$$

Forecast equation (6), a simplified version of equation (5) in which we no longer rely on the estimated value of the error correction term, uses only predetermined variables and does not require any estimated coefficients, so we are free from the constraints of a typical out-of-sample forecast and can make a full set of forecasts for our entire sample period. To evaluate the ability of the benchmark to correctly predict the direction of the change in portfolio inflows, we employ the Pesaran and Timmermann (1992) non-parametric test of predictive failure, which in our case is also a test of whether actual and forecasted changes are independently distributed. If our benchmark predicts the direction of change in portfolio inflows in significantly more than 50 percent of the cases, where significance is assessed using the Pesaran-Timmermann (P-T) statistic, we can reject predictive failure (and the independence of actual and predicted changes) and conclude that the benchmark is useful in predicting flows.

The benchmark performs quite well. For $64 \%$ of the 474 EME observations the benchmark correctly forecasts the direction of the change in portfolio inflows (top half of Table 4). This 
performance is statistically significant, as the P-T test statistic of 6.35 strongly rejects the null hypothesis of predictive failure (and the independence of actual and forecasted changes). For AEs and in the full sample the benchmark also performs well, correctly forecasting the direction of the change in portfolio flows for $67 \%$ of the AE 289 observations of $65 \%$ of all observations.

The benchmark performs well in these one-period-ahead forecasts of directional change, but one must wonder if a simple alternative forecast of reversion — a prediction that the change in flows this period will be the opposite sign of the change in flows last period-also performs well. The reversion forecast (bottom half of Table 4) has directional predictive power, correct 57\%, 65\% and 61\%, respectively, for EMEs, AE, and the full sample. That said, all of the percent correct and P-T statistics are higher for the benchmark forecast. ${ }^{12}$

\section{The Determinants of Deviations from the Benchmark}

Our benchmark flows are analogous to the TvW zero-order flows, but in the language of TvW first-order and second-order shocks push actual flows away from the zero-order flows. In $\mathrm{TvW}$ these shocks are associated with factors that would lead to changes in expectations of returns and risk. We next provide a cursory empirical investigation into deviations from our benchmark, including a standard set of explanatory variables that are at least loosely related to TvW's first- and second-order shocks.

Specifically, to ascertain which factors are associated with short-term deviations in capital inflows from the benchmark - that is, the gap between actual and benchmark inflows-we estimate fixed effects panel regressions in an annual panel dataset that spans 2000 to 2015 and includes 19 EMEs (Table 5). The dependent variable, defined as the deviation (i.e., actual minus benchmark)

\footnotetext{
12 Table 4 shows only total portfolio flows, but in untabulated results we note that the benchmark also performs well
} (at the $1 \%$ significance level) for the bond and equity components. 
divided by GDP, is for portfolio inflows, bond inflows, or equity inflows as indicated in column headings. Independent variables include a parsimonious set of local variables-economic growth, the IMF's inflation forecast, MSCI equity returns, and capital controls—and some global variables (U.S. 10-year Treasury yield, BBB-AAA risk spread, and the VIX). ${ }^{13}$ While we view these regressions as illustrative and not definitive, the results suggest that higher than normal EME portfolio inflows occur when growth is strong, equity returns are high, and US Treasury yields and risk measures (BBB-AAA spread or VIX) are low. Splitting by asset class we find that high equity returns are associated with stronger than normal equity inflows while US Treasury yields and risk measures are more closely linked to bond flows. ${ }^{14}$

\section{Conclusion}

In this paper we frame portfolio flows as fluctuating around some benchmark level. While various notions of benchmark flows are reasonable, our preferred benchmark is simply the amount of flows created if new ROW funds available for investments of any sort (i.e., new ROW savings) are allocated according to lagged portfolio weights, analogous to the Tille and van Wincoop (2010) notion of portfolio growth flows. ${ }^{15}$

Our benchmark flows, which arise from ROW macroeconomic conditions, represent the flows that recipient countries should expect regardless of what occurs in the local economy. Of

\footnotetext{
${ }^{13}$ Capital controls, from Fernandez et al (2016) and specific to the type of inflow (portfolio, bond or equity), are only available through 2015 and thus dictate the end date in the Table 5 regressions. Inflation forecast is a component of the IMF (2016) real policy rate variable.

${ }^{14}$ The sample in Table 4 is limited to 19 EMEs based on the availability of equity returns. Excluding equity returns allows the addition of other EMEs like Panama and Uruguay to bring the sample to 26 EMEs; this larger sample generates a qualitatively similar set of results for the other explanatory variables, although we fail to find a significant impact of risk measures on total portfolio flows.

${ }^{15}$ The reader will note that our preferred benchmark involves an adjustment for China. While we think that adjustment is reasonable and it certainly changes the analysis for at least one country (the US, as shown in Fig. D), none of our empirical results are materially affected by the adjustment. That is, if we conduct all empirical tests using unadjusted data, results for Tables 2-5 and for the model-based out-of-sample forecasts (Fig. 5) are quite similar to the exChina results shown in the paper.
} 
course, actual inflows often deviate from benchmark flows-perhaps because of changes in local or global conditions_-but benchmark flows appear to be a longer-term baseline path around which actual flows oscillate. The relationship between our benchmark and actual flows seems strongest in EMEs. For our sample of 28 EMEs, error correction models suggest that actual portfolio flows adjust strongly toward the benchmark and the benchmark performs well in out-of-sample forecasts of flows.

Overall, both our graphical and empirical results indicate that a comparison of actual and benchmark flows provides a way to ascertain whether sharp slowdowns in capital flows are likely temporary or long-lasting. For example, EME Asia’s portfolio inflows plummeted from US\$155 billion in 2014 to US $\$ 20$ billion in 2015, far below our benchmark, suggesting that the 2015 slowdown would likely be reversed (which indeed occurred in 2016/17). In contrast, the sharp 2015 decline in Latin America's portfolio inflows was a return to benchmark levels, so our analysis suggests that 2016 and 2017 flows should be similar to those in 2015 (which they were). In general, our analysis enables the differentiation of sharp movements away from benchmark levels from sharp movements toward the benchmark. The former (movements away from the benchmark) are likely temporary, whereas the latter (movements toward the benchmark) are likely to be sustained.

Our analysis is also relevant for the current debate on the existence of a global financial cycle (see, for example, Rey (2013) and Cerutti, Claessens and Rose (2017) for two views). Our benchmark flows are tightly connected to ROW GDP, suggesting they are also related to the global business cycle; see Lumsdaine and Prasad (2003), Kose, Otrok and Whiteman (2003), Kose, Otrok, and Prasad (2012), and Ductor and Leiva-Leon (2016), among many others, on comovements in GDP across large economies. By extension, to the extent there is something that can be called a global business cycle, our benchmark suggests there is, at least for benchmark flows, a global capital flow cycle. Actual flows deviate from the benchmark and these deviations may well explain the 
variation in flows (in an $\mathrm{R}^{2}$ sense), but the level of flows appears to be very much driven by benchmark flows (which are tied to ROW global macro conditions).

We close by urging others to conduct similar analysis of other types of capital flows. For direct investment, applying our basic notion seems feasible. New funds available for DI are corporate earnings_-yes, companies can borrow to fund M\&A activity, but new funds come from the flow of corporate earnings—and thus to create benchmark DI flows one just needs to decide on a pre-determined allocation rule. Similarly, we urge experts on banking flows to create benchmarks. 


\section{$\underline{\text { References }}$}

Ahmed, S., S. Curcuru, F. Warnock, and A. Zlate, 2018. Decomposing International Portfolio Flows. mimeo.

Bussière, Matthieu, Julia Schmidt and Natacha Valla, 2016. International financial flows in the new normal:

Key patterns (and why we should care). CEPII Policy Brief No. 10.

Calvo, Guillermo, 1998. Capital Flows and Capital-Market Crises: The Simple Economics of Sudden Stops. Journal of Applied Economics (Nov): 35-54.

Cerutti, Eugenio, Stijn Claessens and Andrew Rose, 2017. How Important is the Global Financial Cycle? Evidence from Capital Flows. NBER WP 23699.

Coeuré, Benoît, 2015. Paradigm lost: Rethinking international adjustments. Egon and Joan von Kashnitz Lecture, Clausen Center for International Business and Policy, Berkeley, 21 November 2015.

Devereux, Michael B., and Alan Sutherland, 2011. Country Portfolios in Open Economy Macro-Models. Journal of the European Economic Association 9(2): 337-369.

Ductor, Lorenzo, and Danilo Leiva-Leon, 2016. Dynamics of global business cycle interdependence. Journal of International Economics 102: 110-127.

Fernandez, Andres, Michael Klein, Alessandro Rebucci, Martin Schindler, and Martin Uribe, 2016. Capital Control Measures: A New Dataset. IMF Economic Review 64: 548-574.

Forbes, Kristin J., and Francis E. Warnock, 2012. Capital flow waves: Surges, stops, flight, and retrenchment. Journal of International Economics 88(2): 235-251.

International Monetary Fund, 2016. Understanding the Slowdown in Capital Flows to Emerging Markets. World Economic Outlook (April): 63-99.

Kao, C., 1999. Spurious regression and residual-based tests for cointegration in panel data. Journal of econometrics, 90(1), pp.1-44.

Kose, M. Ayhan, Christopher Otrok and Charles H. Whiteman, 2003. International Business Cycles: World, Region, and Country-Specific Factors. American Economic Review 93(4): 1216-1239.

Kose, M. Ayhan, Christopher Otrok and Eswar Prasad, 2012. Global Business Cycles: Convergence or Decoupling? International Economic Review 53(2): 511-538.

Kraay, Aart, and Jaume Ventura, 2000. Current accounts in debtor and creditor countries. Quarterly Journal of Economics XCV: 1137-1166.

Kraay, Aart, and Jaume Ventura, 2003. Current accounts in the long and short run. NBER Macroeconomics Annual 2002.

Lane, Philip, and Gian-Maria Milesi-Ferretti, 2017. International Financial Integration in the Aftermath of the Global Financial Crisis. IMF Working Paper WP/17/115.

Leitch, Gordon, and J. Ernest Tanner, 1991. Economic Forecast Evaluation: Profits Versus the Conventional Error Measures. American Economic Review 81(3), 580-590.

Lumsdaine, Robin L. and Eswar Prasad, 2003. Identifying the Common Component of International Economic Fluctuations: A New Approach. The Economic Journal, 113 (January), 101-127.

McCauley, Robert Neil, Agustín S Bénétrix, Patrick McGuire and Goetz von Peter, 2017. Financial deglobalisation in banking? BIS Working Papers No 650.

McQuade, Peter, and Martin Schmitz, 2016. The great moderation in international capital flows: a global phenomenon? ECB Working Paper 1952.

Merton, R. C., 1981. On market timing and investment performance: an equilibrium theory of value for market forecasts. Journal of Business 54, 363-406.

Milesi-Ferretti, Gian-Maria, and Cédric Tille, 2011. The great retrenchment: international capital flows during the global financial crisis. Economic Policy 26(66): 285-342. 
Pedroni, P., 1999. Critical values for cointegration tests in heterogeneous panels with multiple regressors. Oxford Bulletin of Economics and statistics, 61(S1), pp.653-670.

Pedroni, P., 2004. Panel cointegration: asymptotic and finite sample properties of pooled time series tests with an application to the PPP hypothesis. Econometric theory, 20(3), pp.597-625.

Pesaran, M.H., Shin, Y. and Smith, R.P., 1999. Pooled mean group estimation of dynamic heterogeneous panels. Journal of the American Statistical Association, 94(446), pp.621-634.

Pesaran, M. H., and Timmermann, A., 1992. A simple nonparametric test of predictive performance. Journal of Business \& Economic Statistics 10(4), 461-465.

Rey, Hélène, 2013. Dilemma not Trilemma: The Global Financial Cycle and Monetary Policy Independence. in Proceedings of the 2013 Federal Reserve Bank of Kansas City Economic Symposium at Jackson Hole, 285-333.

Schnader, M. H., and H. O. Stekler, 1990. Evaluating Predictions of Change. Journal of Business 63(1), 99-107.

Tille, Cedric, and Eric van Wincoop, 2010. International Capital Flows. Joumal of International Economics 80(2): 157-175. 
Table 1. Portfolio Inflows (selected periods, in billions of US\$)

\begin{tabular}{|c|c|c|c|c|}
\hline & \multicolumn{4}{|c|}{ Total Portfolio Inflows } \\
\hline & 2004-07 & 2008-09 & 2010-14 & $2015-16$ \\
\hline US & 996 & 441 & 619 & 226 \\
\hline Eurozone & 701 & 394 & 421 & 119 \\
\hline AE Other & 769 & 479 & 572 & 335 \\
\hline EME Asia & 63 & 28 & 95 & 42 \\
\hline EME LatAm & 27 & 34 & 120 & 58 \\
\hline EME Other & 46 & -1 & 68 & 5 \\
\hline \multirow[t]{3}{*}{ World } & 2603 & 1374 & 1896 & 785 \\
\hline & \multicolumn{4}{|c|}{ Equity Inflows } \\
\hline & 2004-07 & 2008-09 & 2010-14 & $2015-16$ \\
\hline US & 143 & 173 & 127 & -164 \\
\hline Eurozone & 239 & -46 & 257 & 170 \\
\hline AE Other & 113 & 100 & 139 & -29 \\
\hline EME Asia & 48 & 24 & 48 & 16 \\
\hline EME LatAm & 13 & 16 & 21 & 18 \\
\hline EME Other & 20 & 2 & 10 & 1 \\
\hline \multirow[t]{3}{*}{ World } & 575 & 268 & 602 & 12 \\
\hline & \multicolumn{4}{|c|}{ Bond Inflows } \\
\hline & 2004-07 & 2008-09 & 2010-14 & $2015-16$ \\
\hline US & 853 & 268 & 492 & 390 \\
\hline Eurozone & 462 & 441 & 164 & -51 \\
\hline AE Other & 62 & 379 & 433 & 364 \\
\hline EME Asia & 16 & 4 & 48 & 26 \\
\hline EME LatAm & 14 & 18 & 98 & 40 \\
\hline EME Other & 26 & -4 & 58 & 4 \\
\hline World & 2028 & 1105 & 1293 & 773 \\
\hline
\end{tabular}

Flow data were pulled from the IMF IFS database in Haver Analytics on June 6 2018. In all figures and tables, groupings are largely based on classifications in IMF WEO April 2017.

AE Other: $\quad$ Australia, Canada, Czech Republic, Denmark, Hong Kong, Iceland, Israel, Japan, New Zealand, Norway, Singapore, South Korea, Sweden, Switzerland, United Kingdom

EME Asia: $\quad$ Bangladesh, China, India, Indonesia, Pakistan, Philippines, Thailand

EME LatAm: Argentina, Brazil, Chile, Colombia, Costa Rica, Mexico, Peru, Uruguay

EME Other: Belarus, Bulgaria, Hungary, Kuwait, Macedonia, Mauritius, Panama, Poland, Romania, Russia, South Africa, Turkey, Ukraine 
Table 2. Panel Cointegration Tests

The top portion of the table presents results for Kao (1999) tests, which assume a common cointegrating vector and AR parameter across panels. The bottom panel presents results for Pedroni $(1999,2004)$ tests, which allow for panel specific cointegrating vectors and AR parameters. For all tests we include a panel fixed effect and demean across panels to control for cross-sectional dependence. For Kao tests we report the Modified Dickey-Fuller t-stat and for Pedroni tests we report the Modified Phillips-Perron $t$-stat, in each case with p-values in parentheses. Sample is 2000-2017.

\begin{tabular}{|c|c|c|c|c|}
\hline \multirow[b]{2}{*}{ Test } & \multirow[b]{2}{*}{$\begin{array}{c}\text { Category of } \\
\text { Flows }\end{array}$} & \multicolumn{3}{|c|}{ Sample } \\
\hline & & $\begin{array}{c}\text { Full } \\
(\mathrm{N}=45)\end{array}$ & $\begin{array}{c}\mathbf{A E} \\
(\mathrm{N}=17)\end{array}$ & $\begin{array}{c}\text { EME } \\
(\mathrm{N}=28)\end{array}$ \\
\hline \multirow{3}{*}{ Као } & Portfolio & $\begin{array}{l}-12.40 \\
(0.000)\end{array}$ & $\begin{array}{c}-8.10 \\
(0.000)\end{array}$ & $\begin{array}{c}-4.92 \\
(0.000)\end{array}$ \\
\hline & Equity & $\begin{array}{c}-9.37 \\
(0.000) \\
\end{array}$ & $\begin{array}{c}-5.44 \\
(0.016) \\
\end{array}$ & $\begin{array}{c}-1.36 \\
(0.087) \\
\end{array}$ \\
\hline & Bonds & $\begin{array}{c}-9.06 \\
(0.000)\end{array}$ & $\begin{array}{c}-5.67 \\
(0.000)\end{array}$ & $\begin{array}{c}-3.07 \\
(0.001)\end{array}$ \\
\hline \multirow{3}{*}{ Pedroni } & Portfolio & $\begin{array}{c}-3.71 \\
(0.000)\end{array}$ & $\begin{array}{l}-1.749 \\
(0.040)\end{array}$ & $\begin{array}{c}-6.06 \\
(0.000)\end{array}$ \\
\hline & Equity & $\begin{array}{c}-10.41 \\
(0.000) \\
\end{array}$ & $\begin{array}{c}-6.26 \\
(0.000)\end{array}$ & $\begin{array}{c}-7.40 \\
(0.000)\end{array}$ \\
\hline & Bonds & $\begin{array}{c}-0.52 \\
(0.298)\end{array}$ & $\begin{array}{c}0.245 \\
(0.403)\end{array}$ & $\begin{array}{c}-2.10 \\
(0.018)\end{array}$ \\
\hline
\end{tabular}


Table 3. Pooled Mean Group Error Correction Models

The table presents results from pooled mean group error correction regressions of the form $\Delta$ flows $i t=$ $\alpha_{i}+\beta_{i} \Delta$ bmark $_{i t}+\lambda_{i}\left(\right.$ flows $_{i, t-1}-\theta$ bmark $\left._{i, t-1}\right)+\mu_{i t}$, estimated for the sample period 2000-2017. In the final column the error correction model is flipped such that $\Delta$ bmark, is the dependent variable. The model estimates panel specific error correction terms $\left(\lambda_{i}\right)$; we report the cross-panel average. Standard errors are in parentheses; ${ }^{* * *},{ }^{* *}$, and $*$ denote significance at the 1,5 , and 10 percent levels, respectively.

\begin{tabular}{|c|c|c|c|c|}
\hline & \multicolumn{3}{|c|}{ LHS $=\Delta$ flows $_{t}$} & LHS $=\Delta b m a r k_{t}$ \\
\hline & $\begin{array}{c}\text { Full Sample } \\
\text { Portfolio Flows } \\
\text { (1) }\end{array}$ & $\begin{array}{c}\text { AE } \\
\text { Portfolio Flows } \\
\text { (2) }\end{array}$ & $\begin{array}{c}\text { EME } \\
\text { Portfolio Flows } \\
\text { (3) }\end{array}$ & $\begin{array}{c}\text { EME } \\
\text { Portfolio Flows } \\
\text { (4) }\end{array}$ \\
\hline $\begin{array}{c}\text { Long Run } \\
\text { Benchmark }(\theta)\end{array}$ & $\begin{array}{c}0.283^{* * *} \\
(0.110)\end{array}$ & $\begin{array}{c}0.015 \\
(0.136) \\
\end{array}$ & $\begin{array}{c}0.976 * * * \\
(0.156)\end{array}$ & $\begin{array}{c}0.624^{* * *} \\
(0.190)\end{array}$ \\
\hline $\begin{array}{l}\text { Short Run Gap }(\lambda) \\
\text { (error correction) }\end{array}$ & $\begin{array}{c}-0.758^{* * *} \\
(0.050) \\
\end{array}$ & $\begin{array}{c}-0.819 * * * \\
(0.083) \\
\end{array}$ & $\begin{array}{c}-0.751^{* * *} \\
(0.068) \\
\end{array}$ & $\begin{array}{c}0.034 * * * \\
(0.006) \\
\end{array}$ \\
\hline \# observations & 789 & 303 & 486 & 486 \\
\hline \# countries & 45 & 17 & 28 & 28 \\
\hline
\end{tabular}




\section{Table 4. Directional Forecasting}

The table presents results from the Pesaran-Timmermann (1992) non-parametric test for the accuracy of a directional forecast for the period from 2001 through 2017. The benchmark (BM) gap forecast is formed by $\Delta$ flows $_{i, t}{ }_{i, t}=-\left(\right.$ flows $_{i, t-1}-$ bmark $\left._{i, t-1}\right)$. The "Reversion" forecast predicts the change in flows this period will be the opposite of the change in flows last period: $\Delta$ flows $^{e}{ }_{i, t}=-\left(\Delta\right.$ flows $\left._{i, t-1}\right)$. In each case we present the fraction of observations for which the forecast correctly predicts the sign of $\Delta$ flows (\% correct) and the Pesaran-Timmermann (P-T) statistic, which is distributed normally and has a null hypothesis of no directional predictive power. The $1 \%$ critical value for the P-T test is 2.33 . The EME sample has two observations fewer than 17 times 28 because we do not have 2000 benchmark amounts for Kuwait and Romania.

\begin{tabular}{|l|l|l|l|l|}
\hline & & EME & AE & All \\
\hline BM gap forecast & \% correct & $63.9 \%$ & $67.4 \%$ & $65.3 \%$ \\
\hline & P-T stat & 6.35 & 5.92 & 8.58 \\
\hline Reversion forecast & \% correct & $57.1 \%$ & $65.4 \%$ & $61.3 \%$ \\
\hline & P-T stat & 3.60 & 5.40 & 6.75 \\
\hline & \# obs & 474 & 289 & 763 \\
\hline
\end{tabular}




\section{Table 5. Determinants of Deviations: EMEs}

Fixed effects panel regressions use an annual panel dataset that spans 2000 to 2015 and includes 19 EMEs. The dependent variable, defined as the deviation (i.e., actual minus benchmark) divided by GDP, is for portfolio inflows, bond inflows, or equity inflows as indicated in column headings. Independent variables include local variables (economic growth, IMF inflation forecast, MSCI equity returns, and capital controls) and global variables (U.S. 10-year Treasury yield, BBB-AAA risk spread, and the VIX). Constants are included but not reported. Robust standard errors, clustered at the country level, are reported in parentheses. ***, ** and $*$ denote significance levels at $1 \%, 5 \%$ and $10 \%$, respectively.

\begin{tabular}{|c|c|c|c|c|c|c|}
\hline & Portfolio & Portfolio & Bonds & Bonds & Equity & Equity \\
\hline Growth & $\begin{array}{c}0.131^{* * *} \\
(0.039)\end{array}$ & $\begin{array}{c}0.133 * * * \\
(0.040)\end{array}$ & $\begin{array}{l}0.088^{* *} \\
(0.040)\end{array}$ & $\begin{array}{l}0.091^{* *} \\
(0.040)\end{array}$ & $\begin{array}{l}0.032 * * * \\
(0.011)\end{array}$ & $\begin{array}{l}0.037 * * * \\
(0.011)\end{array}$ \\
\hline Inflation & $\begin{array}{l}-0.012 \\
(0.024)\end{array}$ & $\begin{array}{l}-0.012 \\
(0.024)\end{array}$ & $\begin{array}{l}-0.017 \\
(0.023)\end{array}$ & $\begin{array}{l}-0.017 \\
(0.023)\end{array}$ & & \\
\hline US Treasury yield & $\begin{array}{c}-0.293^{*} \\
(0.148)\end{array}$ & $\begin{array}{c}-0.360 * * \\
(0.140)\end{array}$ & $\begin{array}{l}-0.354^{* *} \\
(0.141)\end{array}$ & $\begin{array}{l}-0.423^{* * *} \\
(0.126)\end{array}$ & $\begin{array}{c}0.061 \\
(0.078)\end{array}$ & $\begin{array}{c}0.042 \\
(0.072)\end{array}$ \\
\hline$V I X$ & $\begin{array}{c}-0.033^{* *} \\
(0.015)\end{array}$ & & $\begin{array}{c}-0.035^{* * *} \\
(0.011)\end{array}$ & & $\begin{array}{l}-0.012 \\
(0.012)\end{array}$ & \\
\hline$B B B-A A A$ spread & & $\begin{array}{c}-0.303^{* *} \\
(0.138)\end{array}$ & & $\begin{array}{l}-0.320^{* *} \\
(0.134)\end{array}$ & & $\begin{array}{l}-0.039 \\
(0.092)\end{array}$ \\
\hline Equity Returns & $\begin{array}{c}1.218^{* * *} \\
(0.246)\end{array}$ & $\begin{array}{c}1.345 * * * \\
(0.237)\end{array}$ & & & $\begin{array}{l}0.630^{* * *} \\
(0.162)\end{array}$ & $\begin{array}{l}0.679 * * * \\
(0.170)\end{array}$ \\
\hline Capital Controls & $\begin{array}{r}1.486 \\
(1.212)\end{array}$ & $\begin{array}{l}1.470 \\
(1.204)\end{array}$ & $\begin{array}{r}1.373 \\
(0.951)\end{array}$ & $\begin{array}{r}1.379 \\
(0.964)\end{array}$ & $\begin{array}{l}-0.246 \\
(0.367)\end{array}$ & $\begin{array}{l}-0.232 \\
(0.365)\end{array}$ \\
\hline$R^{2}$ & 0.19 & 0.19 & 0.14 & 0.14 & 0.16 & 0.16 \\
\hline$N$ & 285 & 285 & 283 & 283 & 285 & 285 \\
\hline
\end{tabular}


Figure 1. Portfolio Flows into Emerging Market Economies

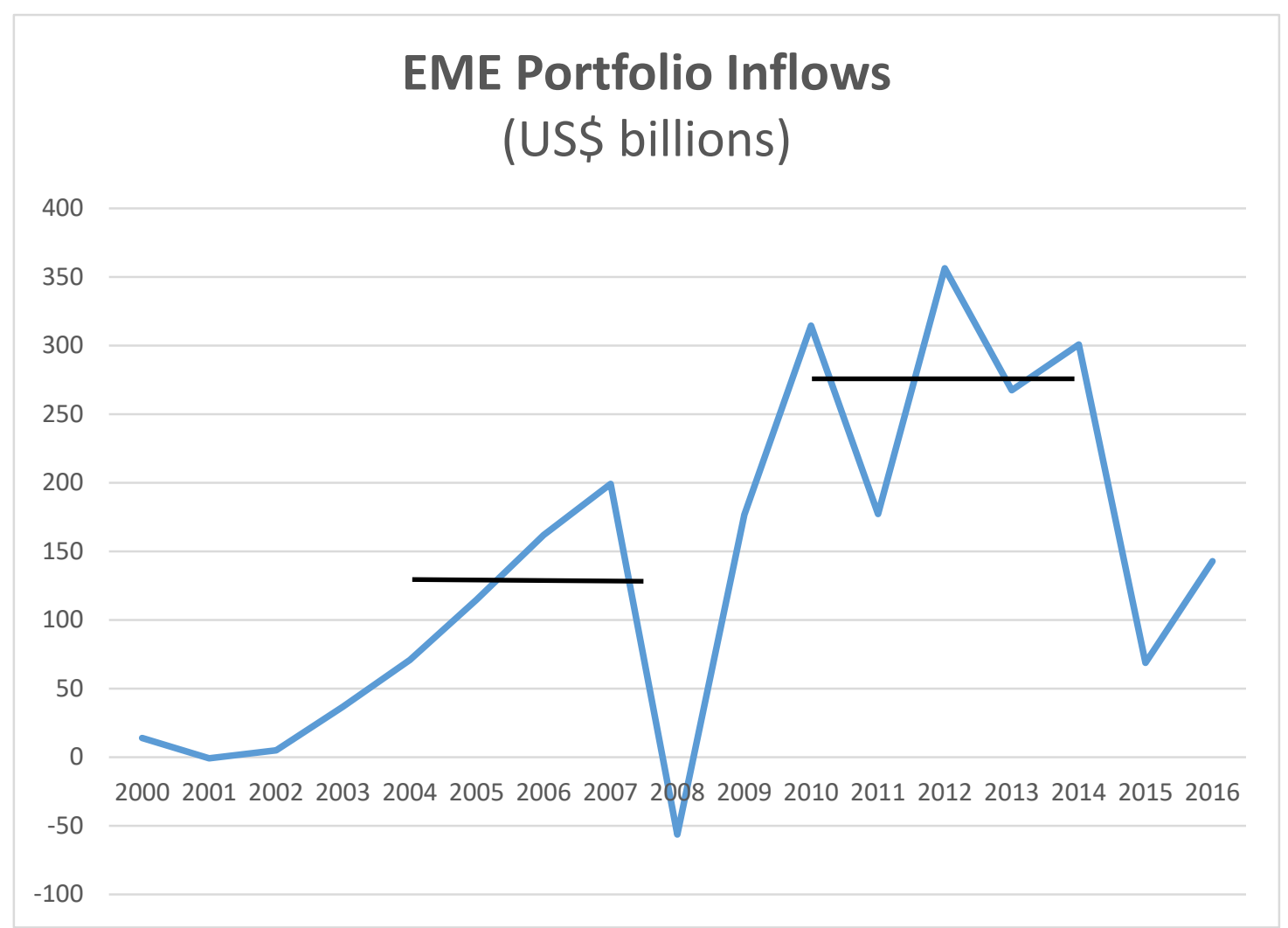

Note: Data are through 2016. Horizontal lines are averages for the 2004-2007 and 2010-2014 periods. 
Figure 2. Portfolio Inflows through 2016 (in billions of US\$)

Country groupings are in Table 1.
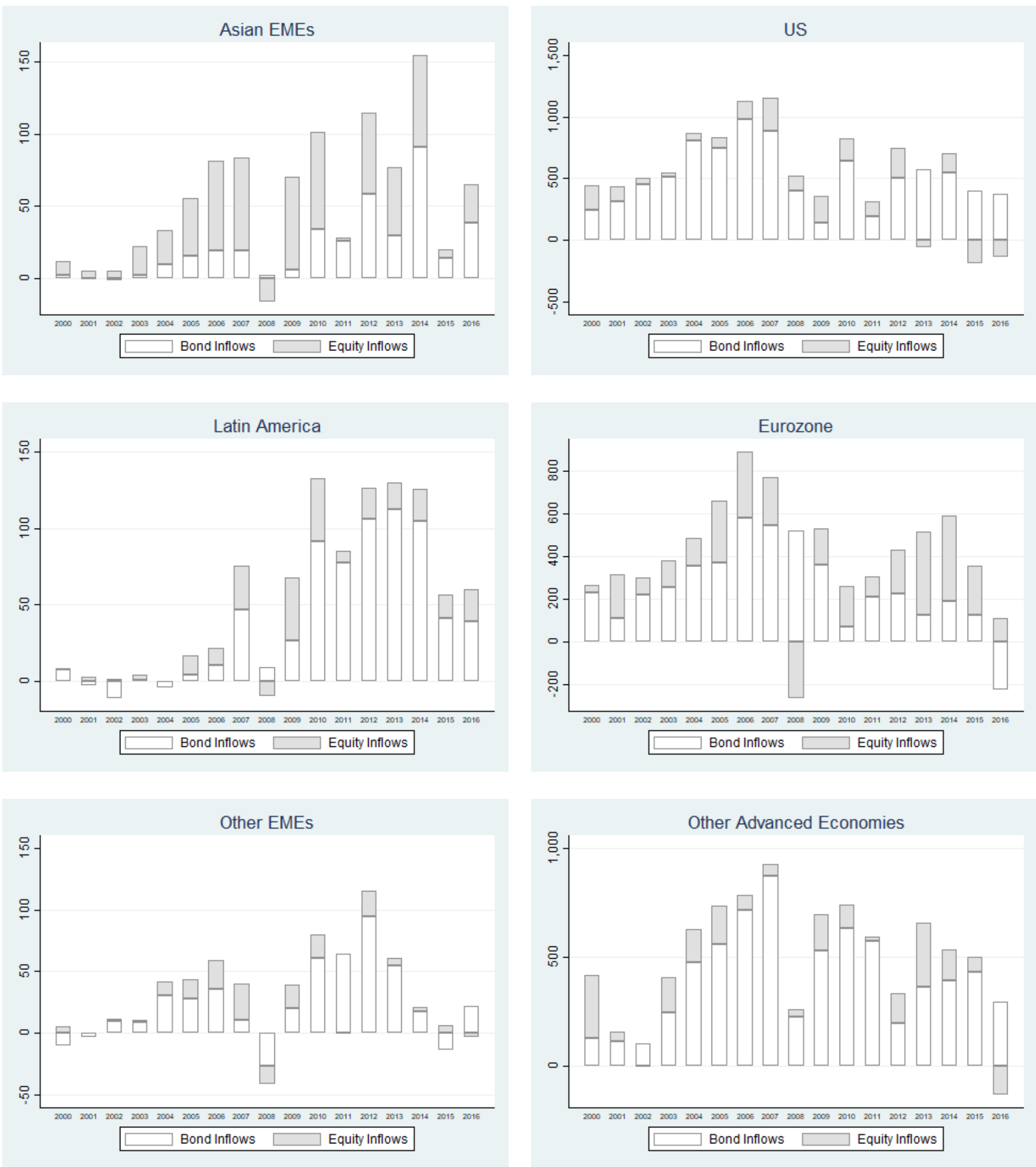


\section{Figure 3. From GDP through Savings to Benchmark Flows}

Benchmark flows in this figure use the ROW approach with the exChina adjustment and a trailing 5-year average for portfolio weights. "Global" is the set of countries in our full sample. The final chart depicts benchmark flows along with its amount if portfolio weights were held constant at 2000 levels.

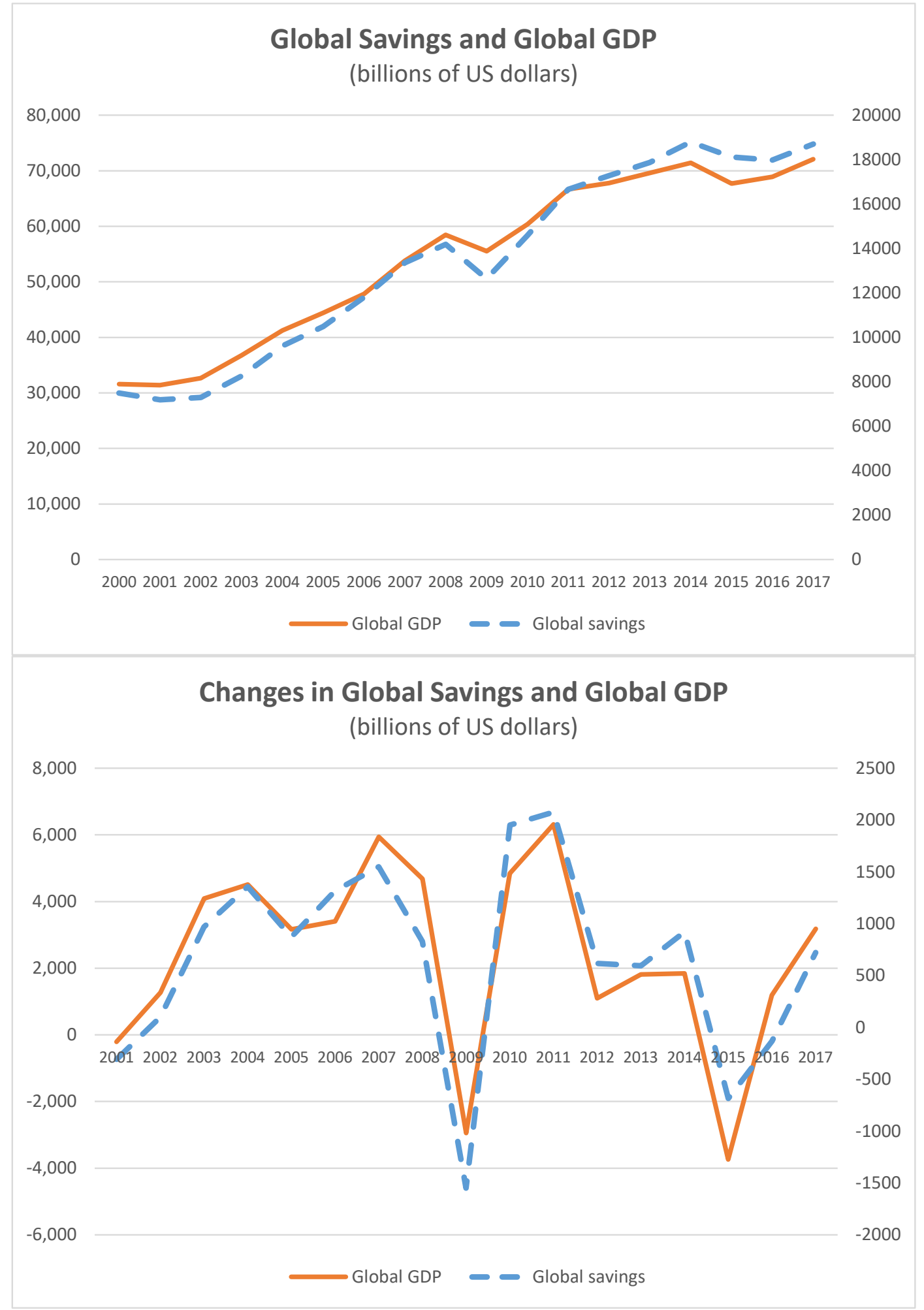




\section{Global Benchmark Portfolio Flows and Global GDP \\ (billions of US dollars)}

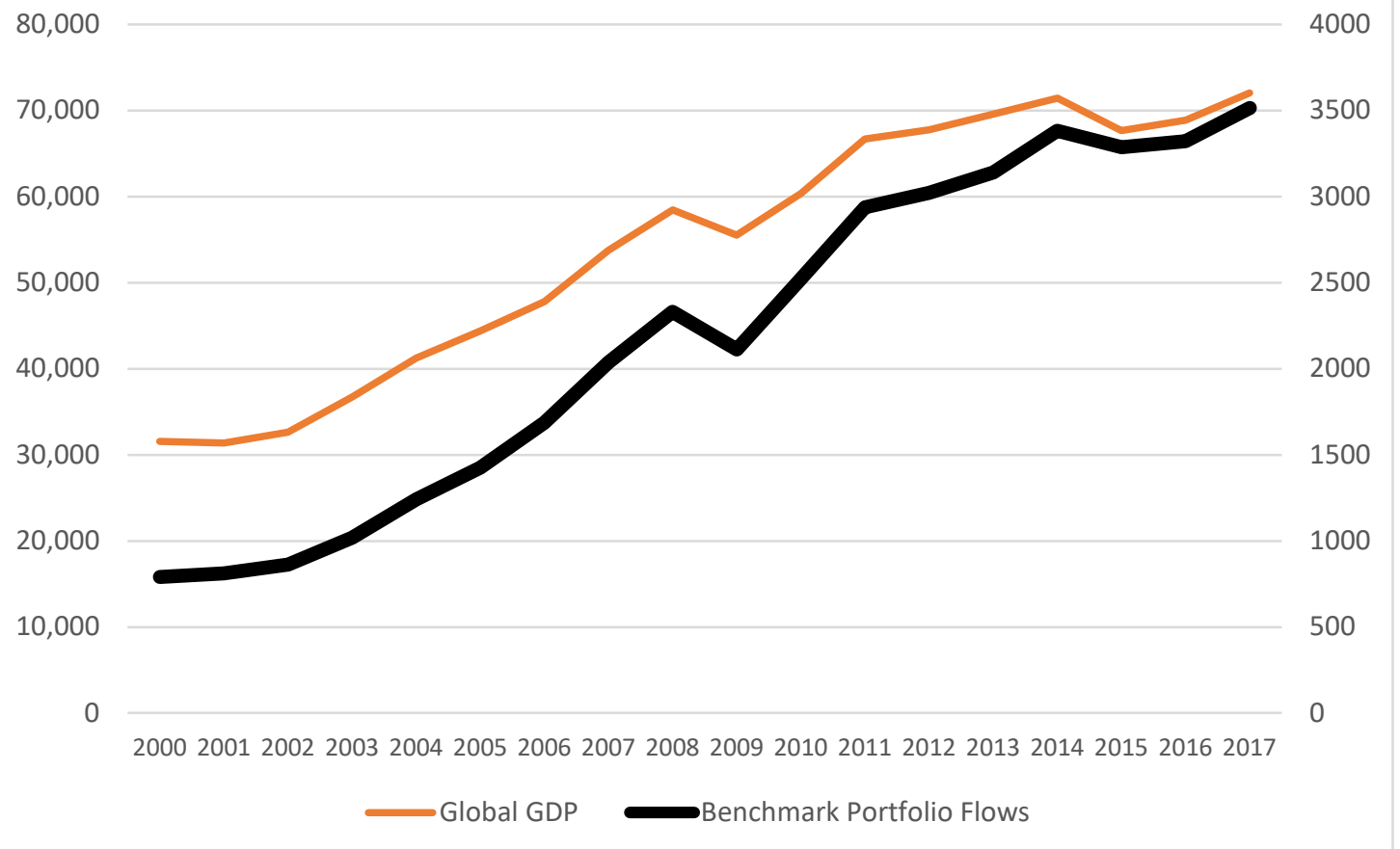

\section{Global Benchmark Portfolio Flows: \\ Actual and with Fixed Weights \\ (billions of US dollars)}

4,000

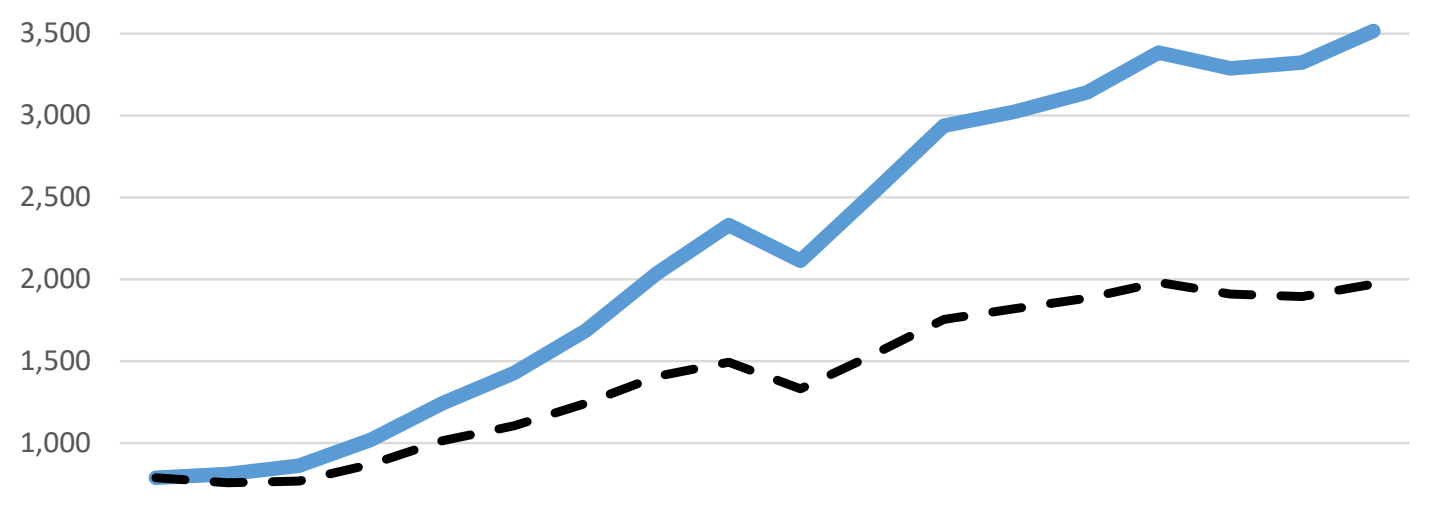

500

0

200020012002200320042005200620072008200920102011201220132014201520162017

Benchmark Portfolio Flows $\quad$ - - fixed weight 
Figure 4. Actual and Benchmark Inflows: Portfolio, Equity and Bond (billions of USD)
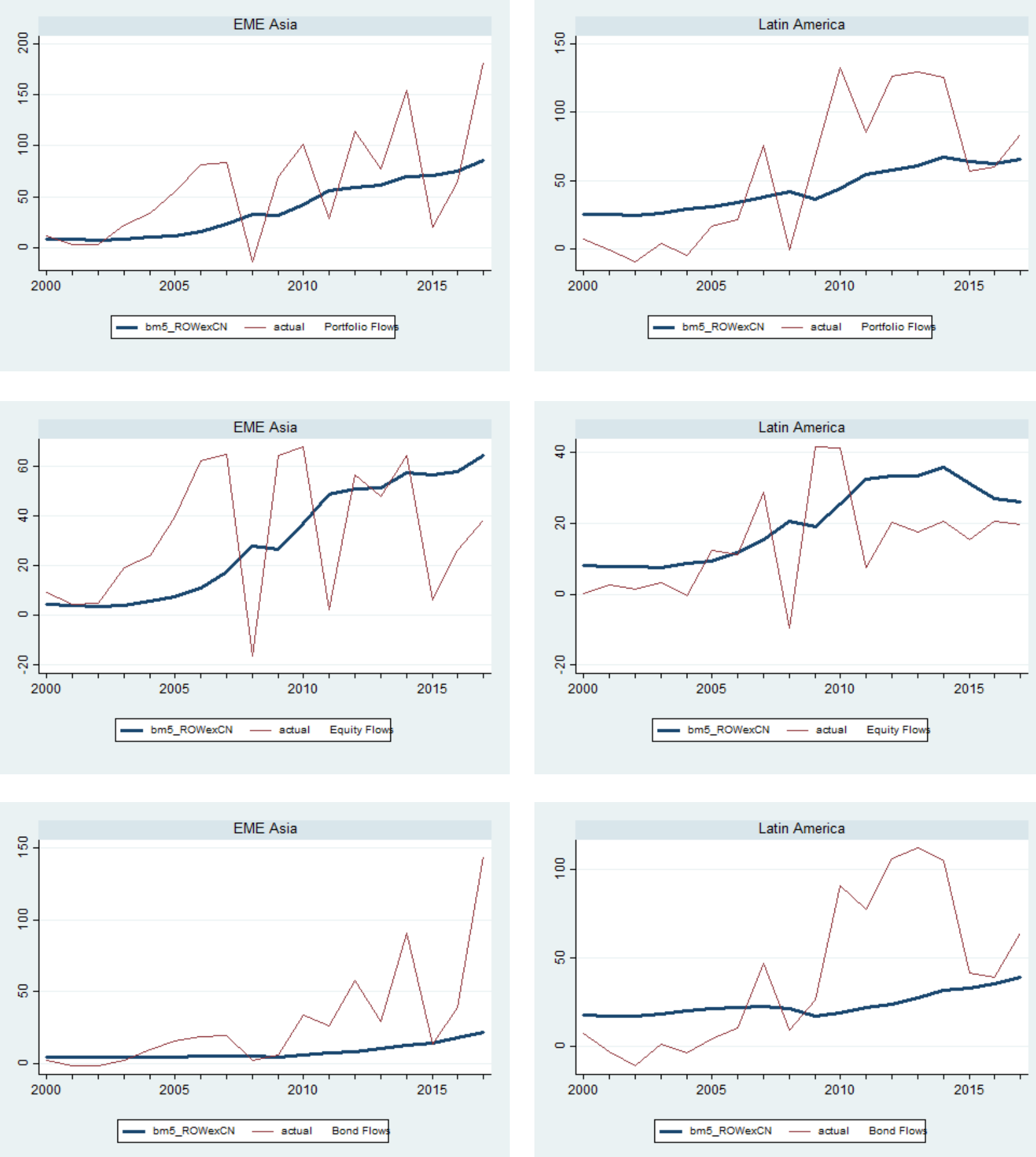

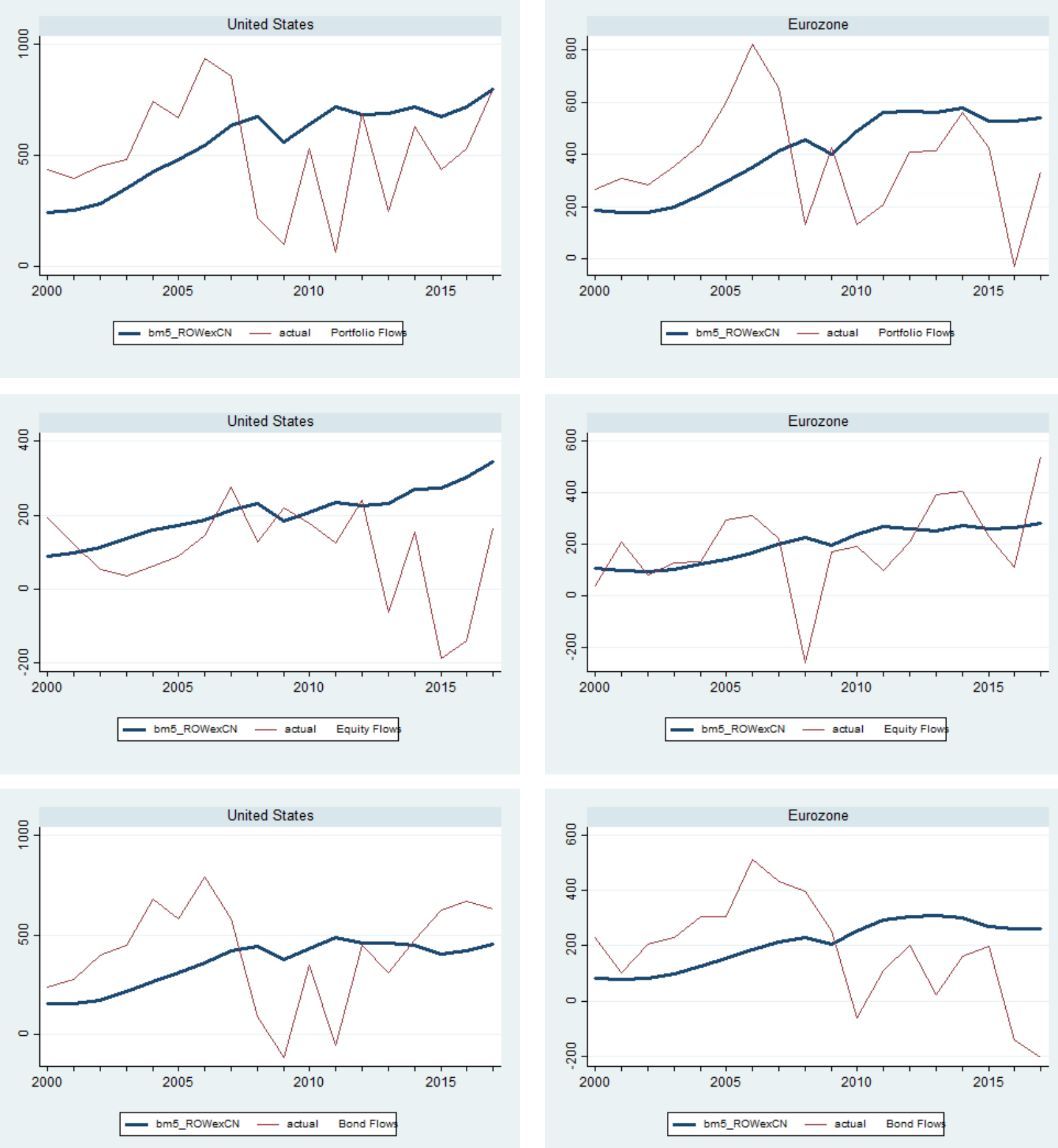

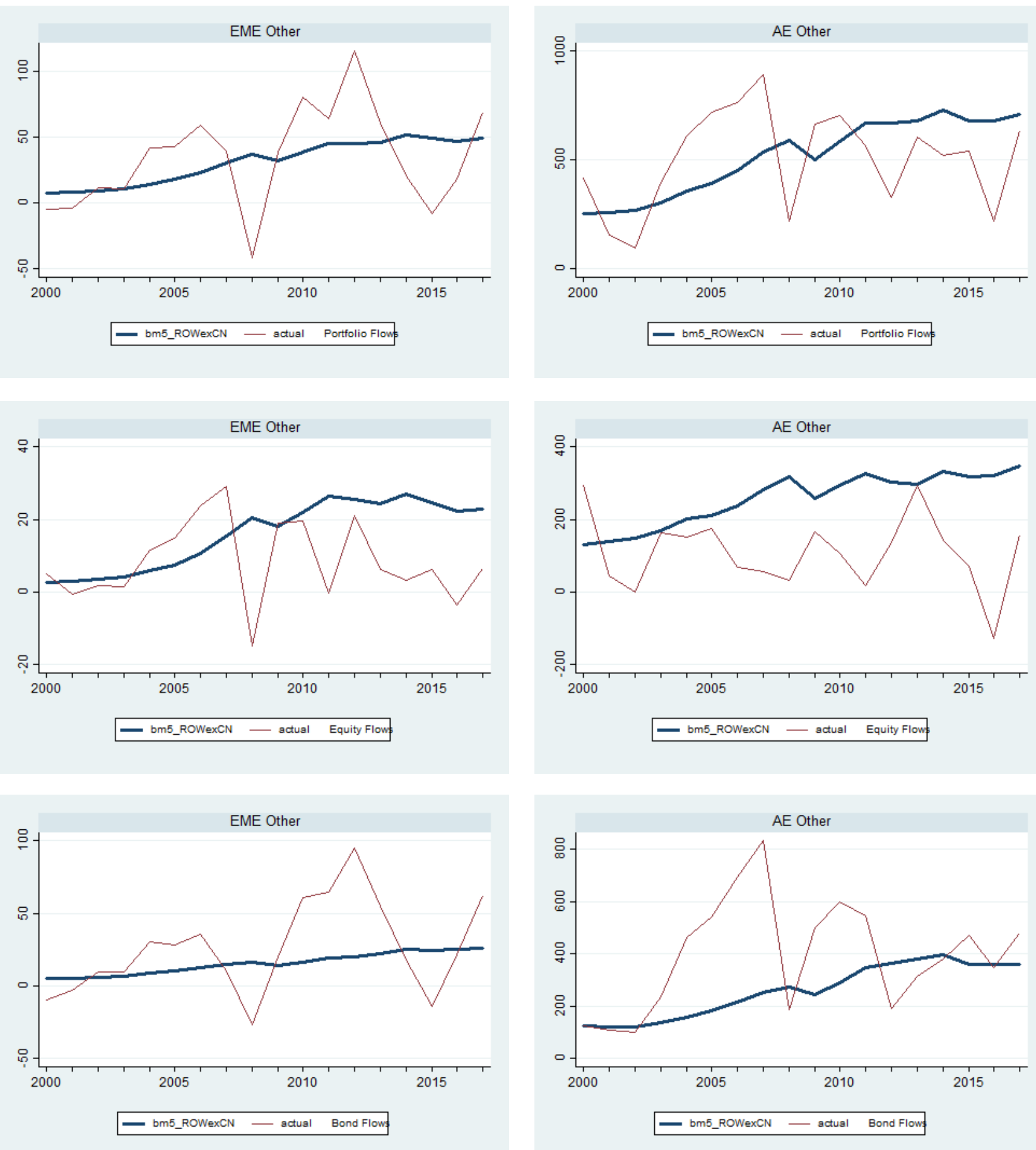
Figure 5. Model-based Forecasts of Changes in EME Portfolio Inflows

a. Forecasting 2015, 2016 and 2017 based on model estimated from 2000 to 2014

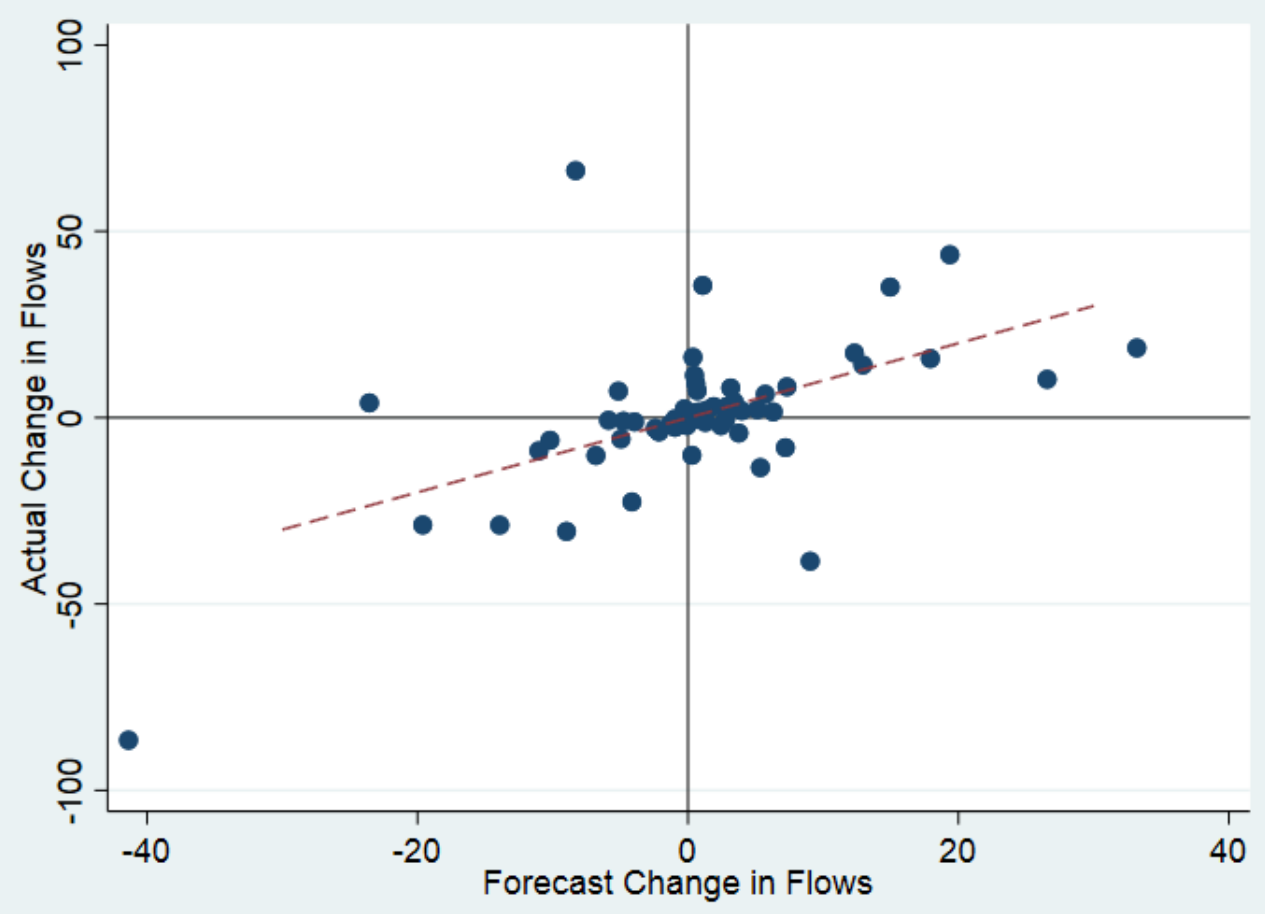

b. Forecasting 2017 based on model estimated from 2000 to 2016

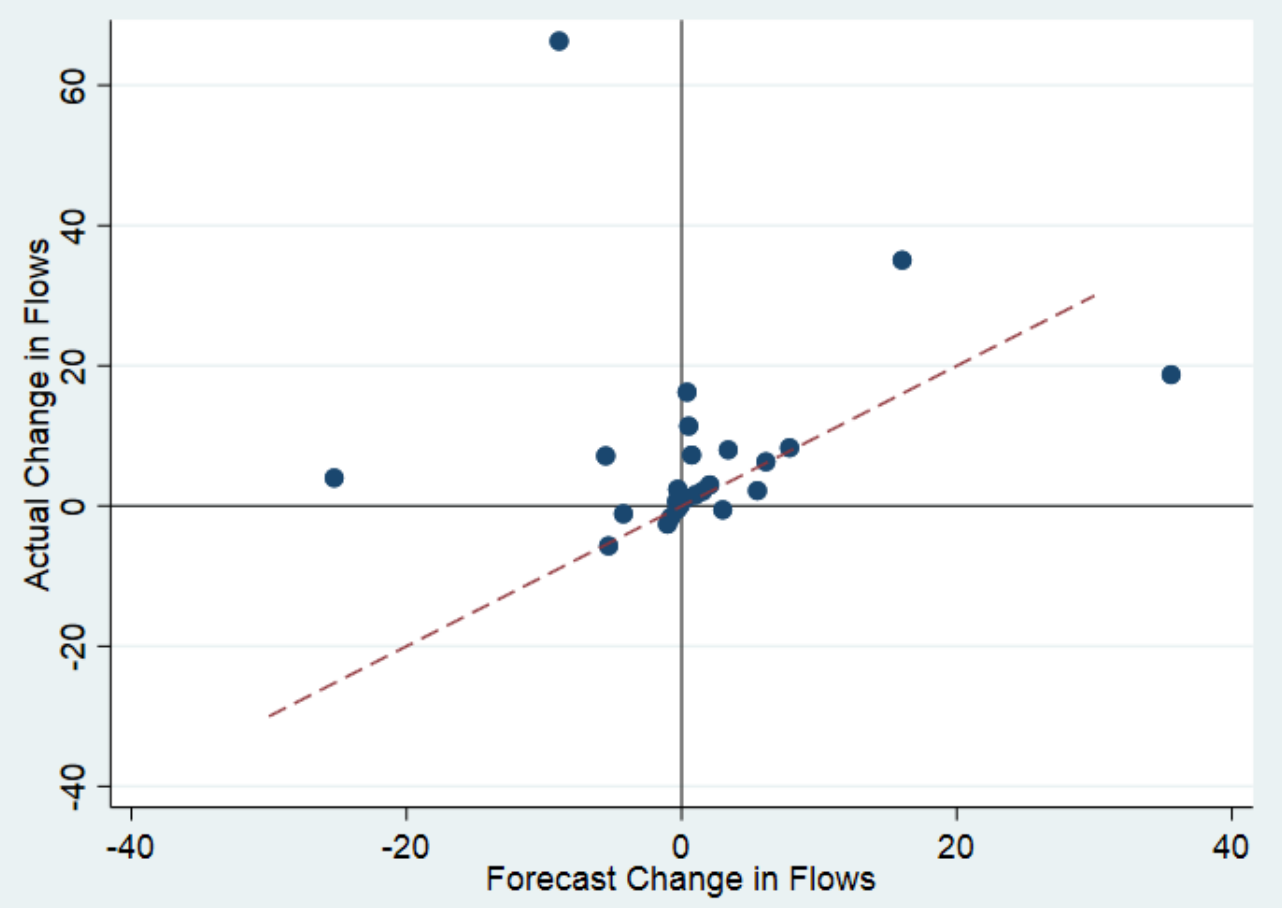




\section{Appendix. Actual and Benchmark Inflows for Selected Countries (billions of USD)}

a. Other Advanced Economies
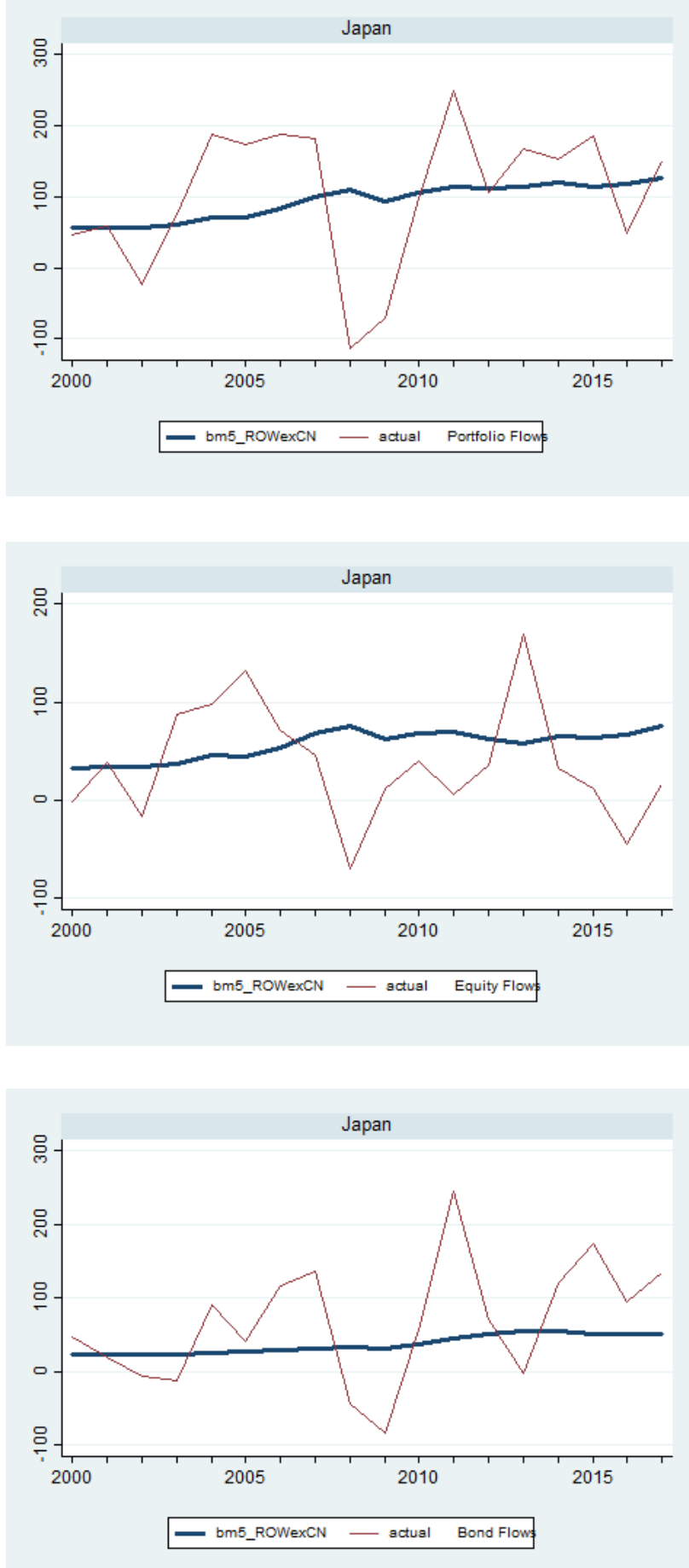
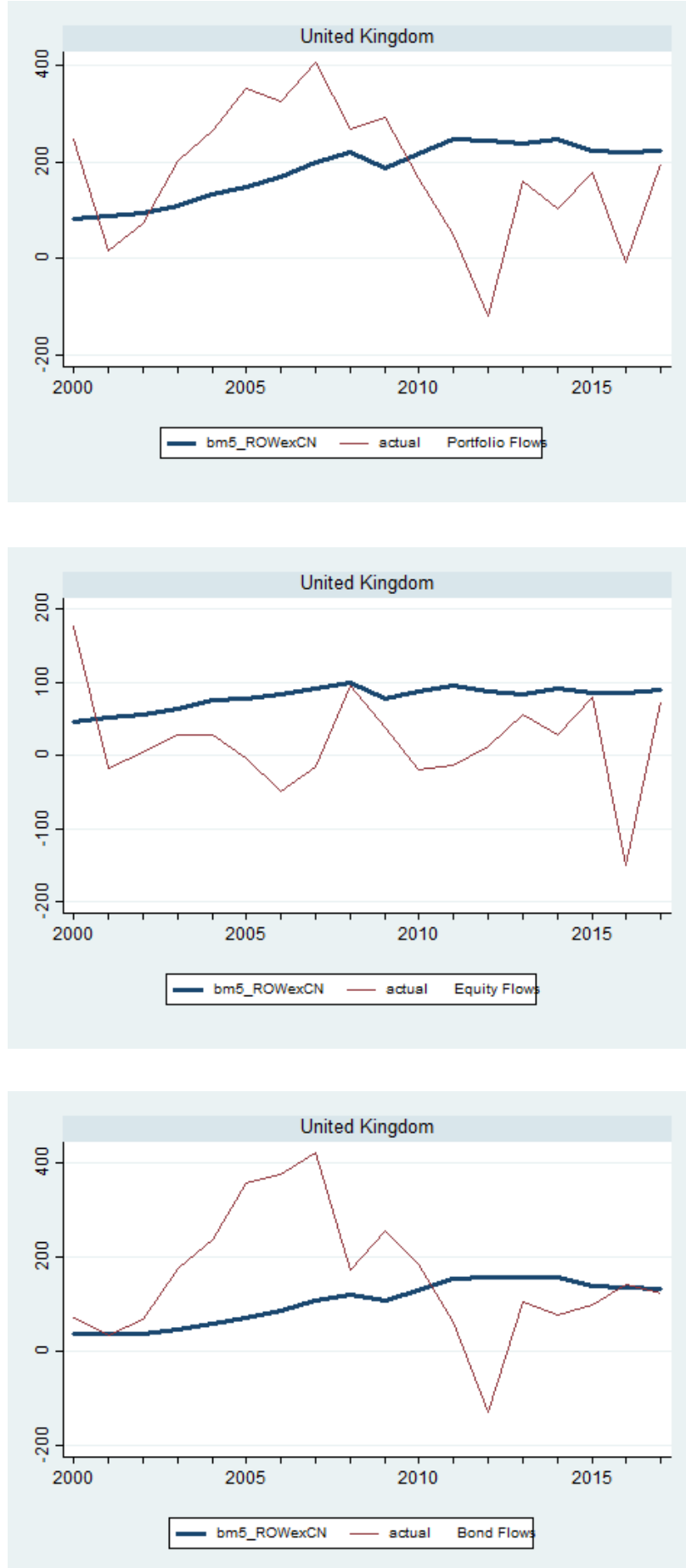

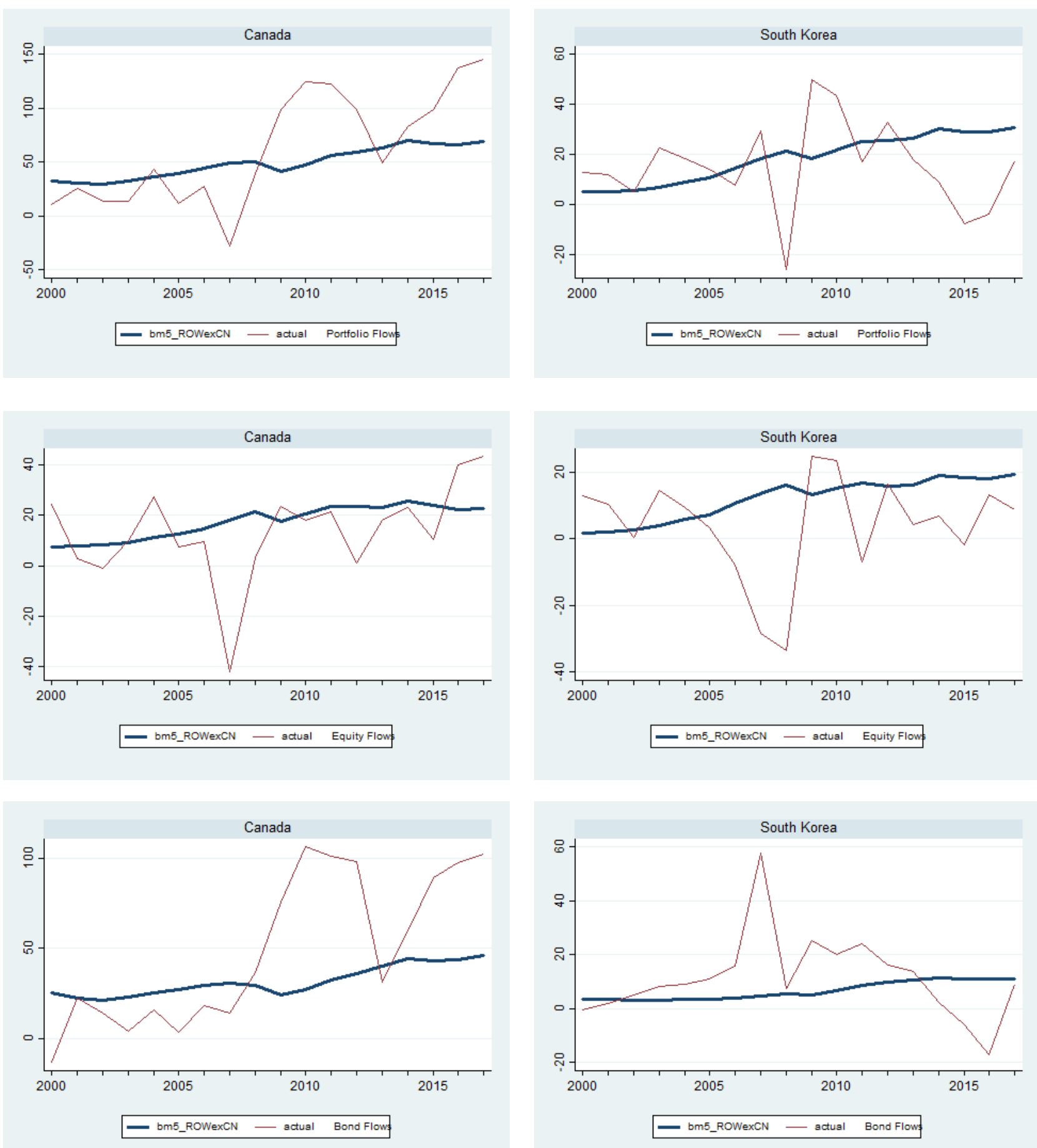

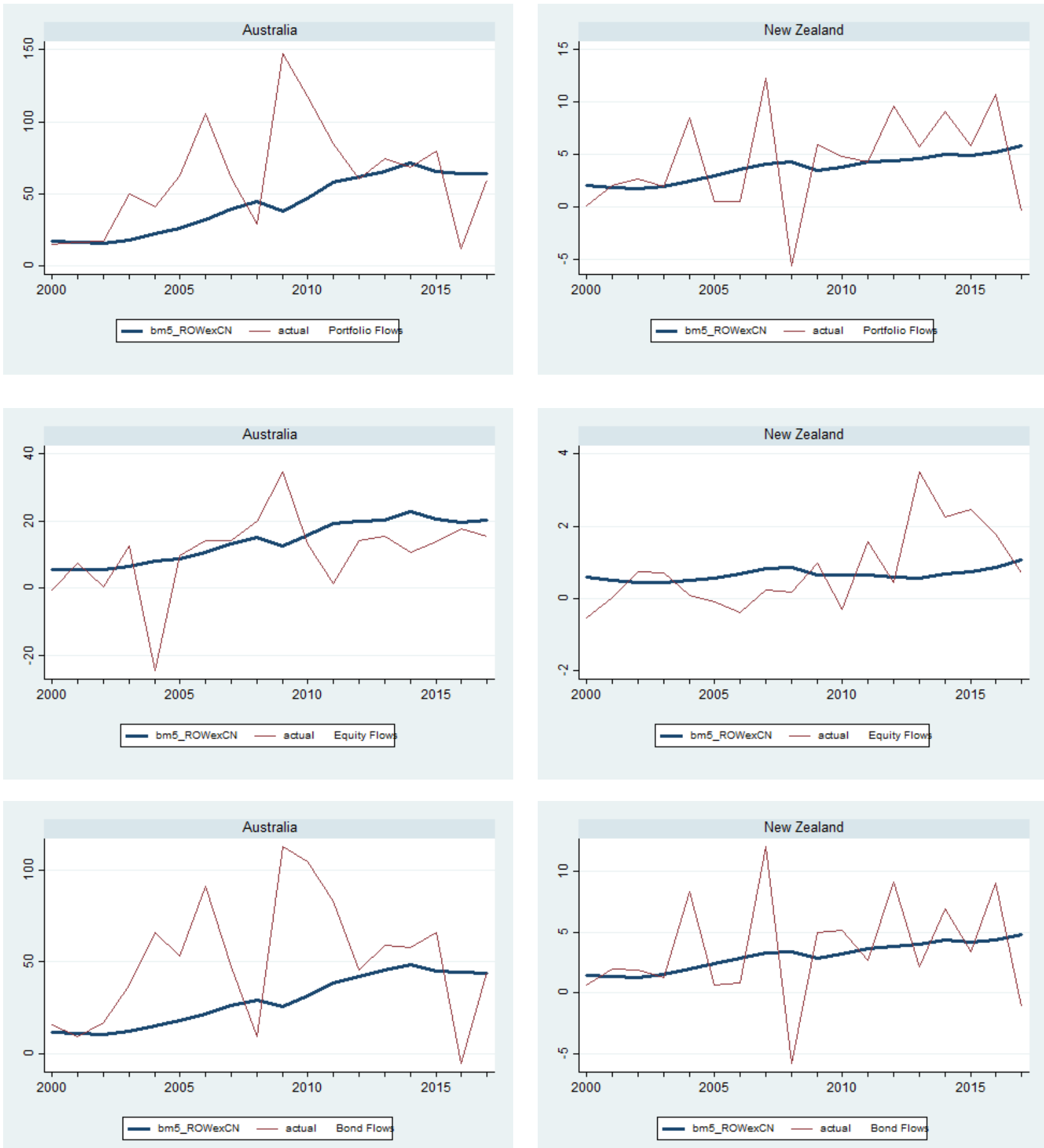
b. Latin America
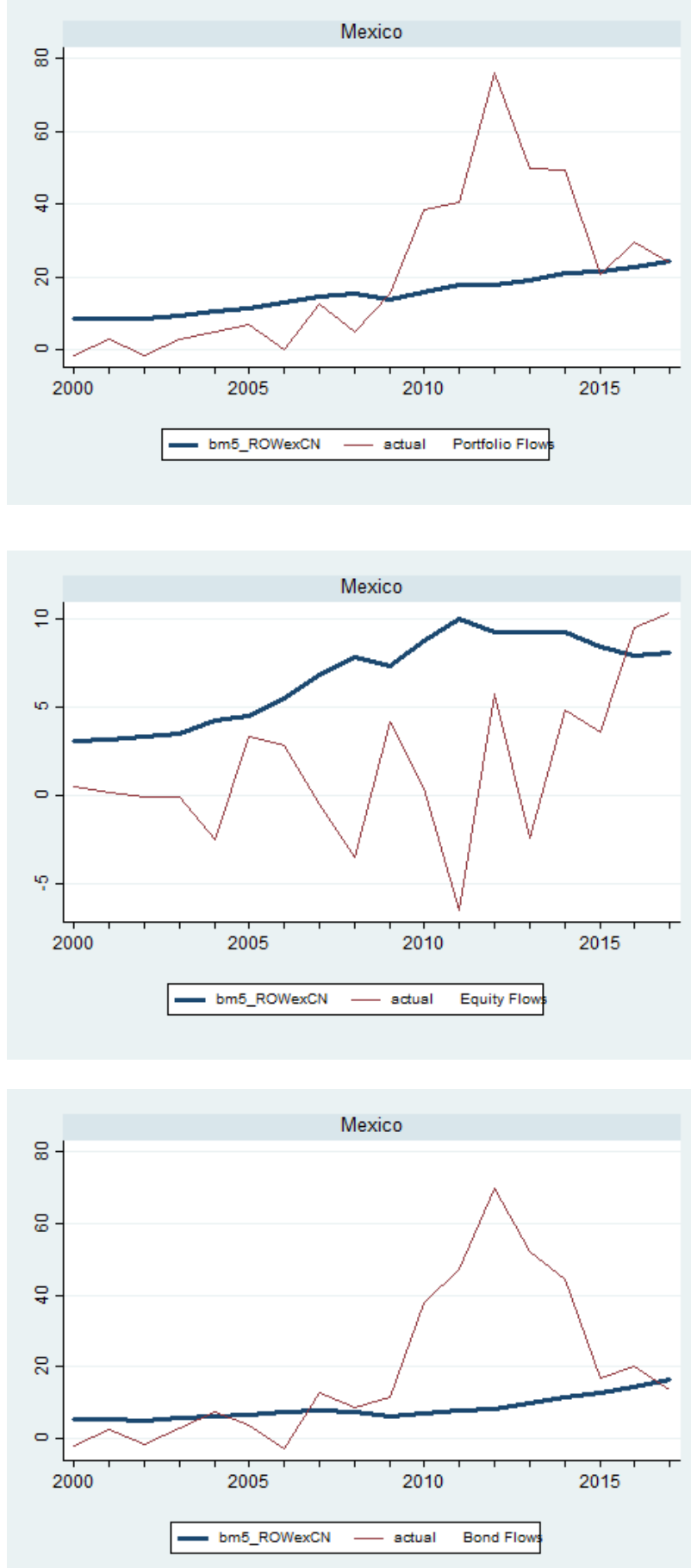
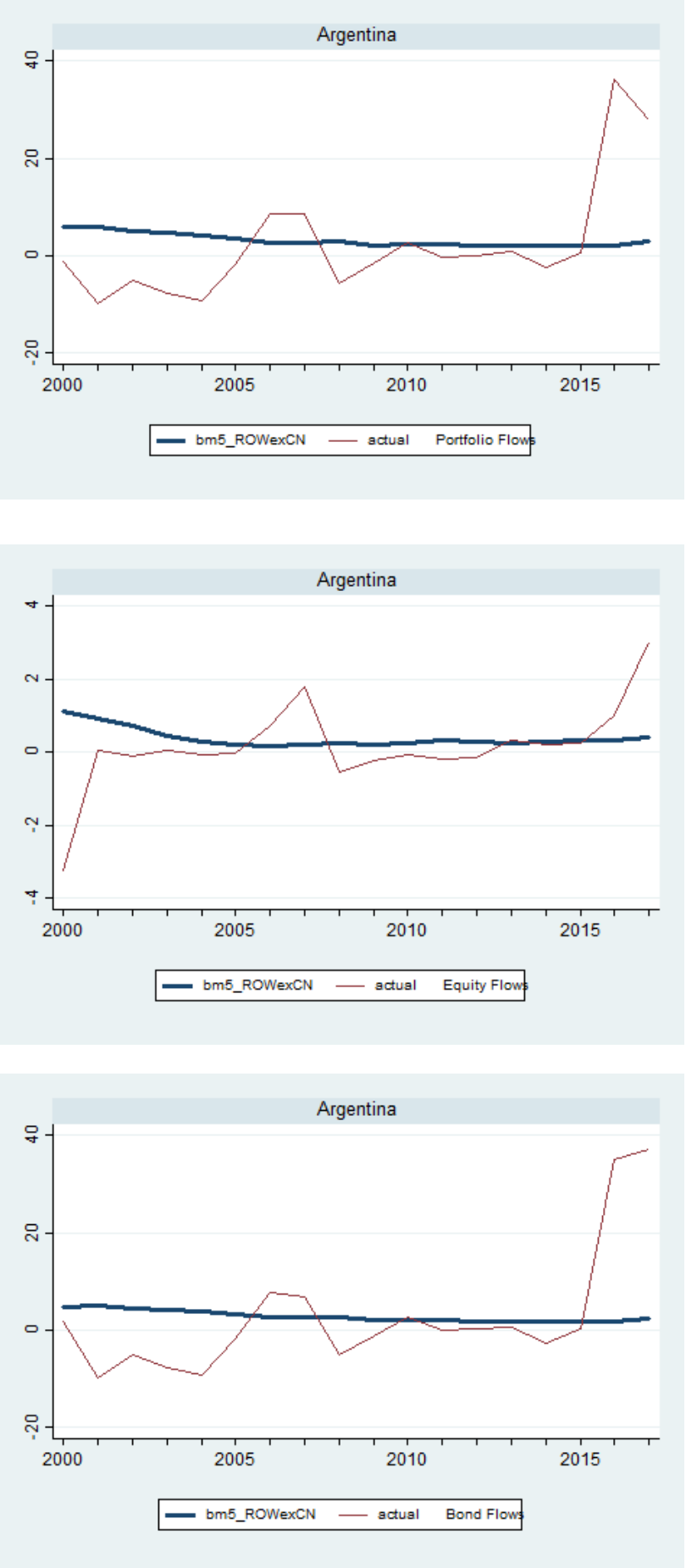
b. Latin America, continued
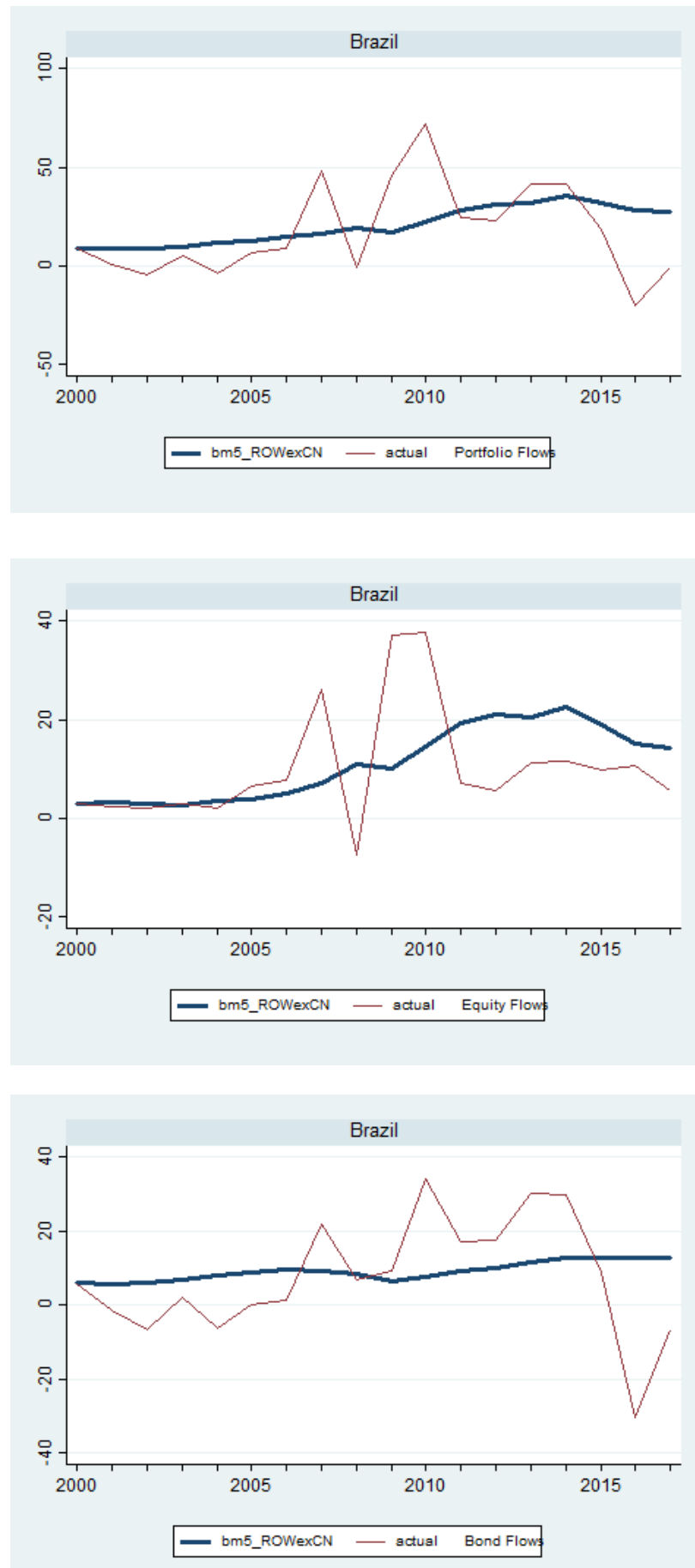

c. EME Asia
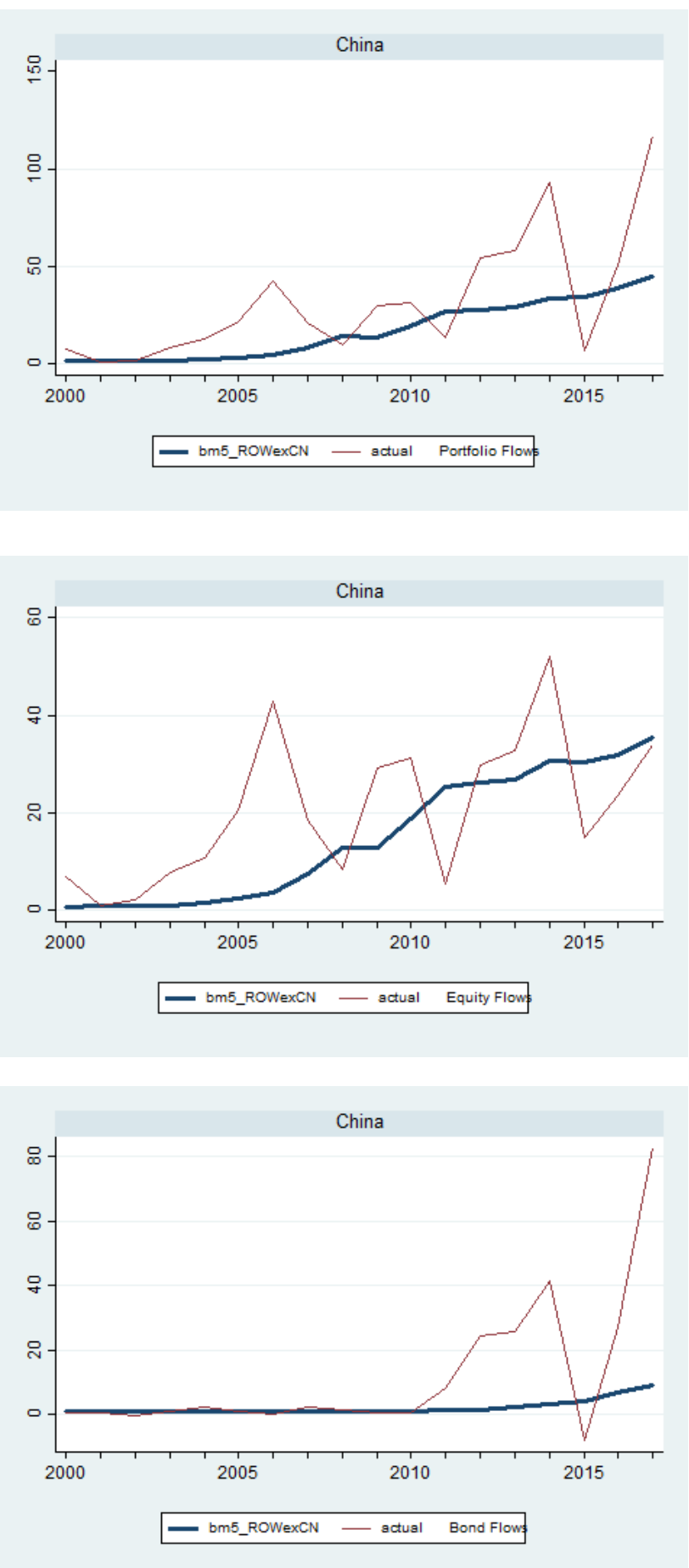

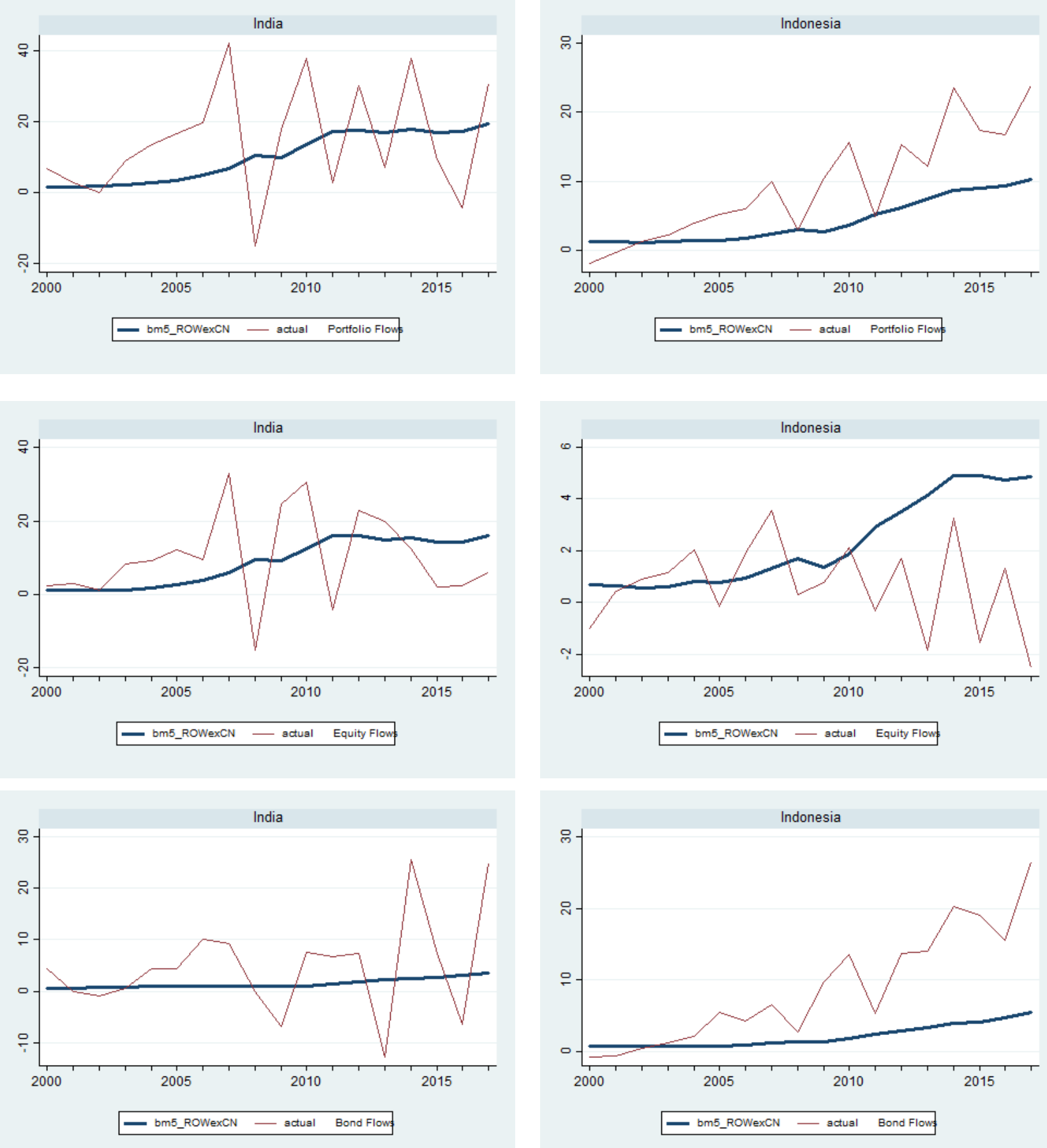

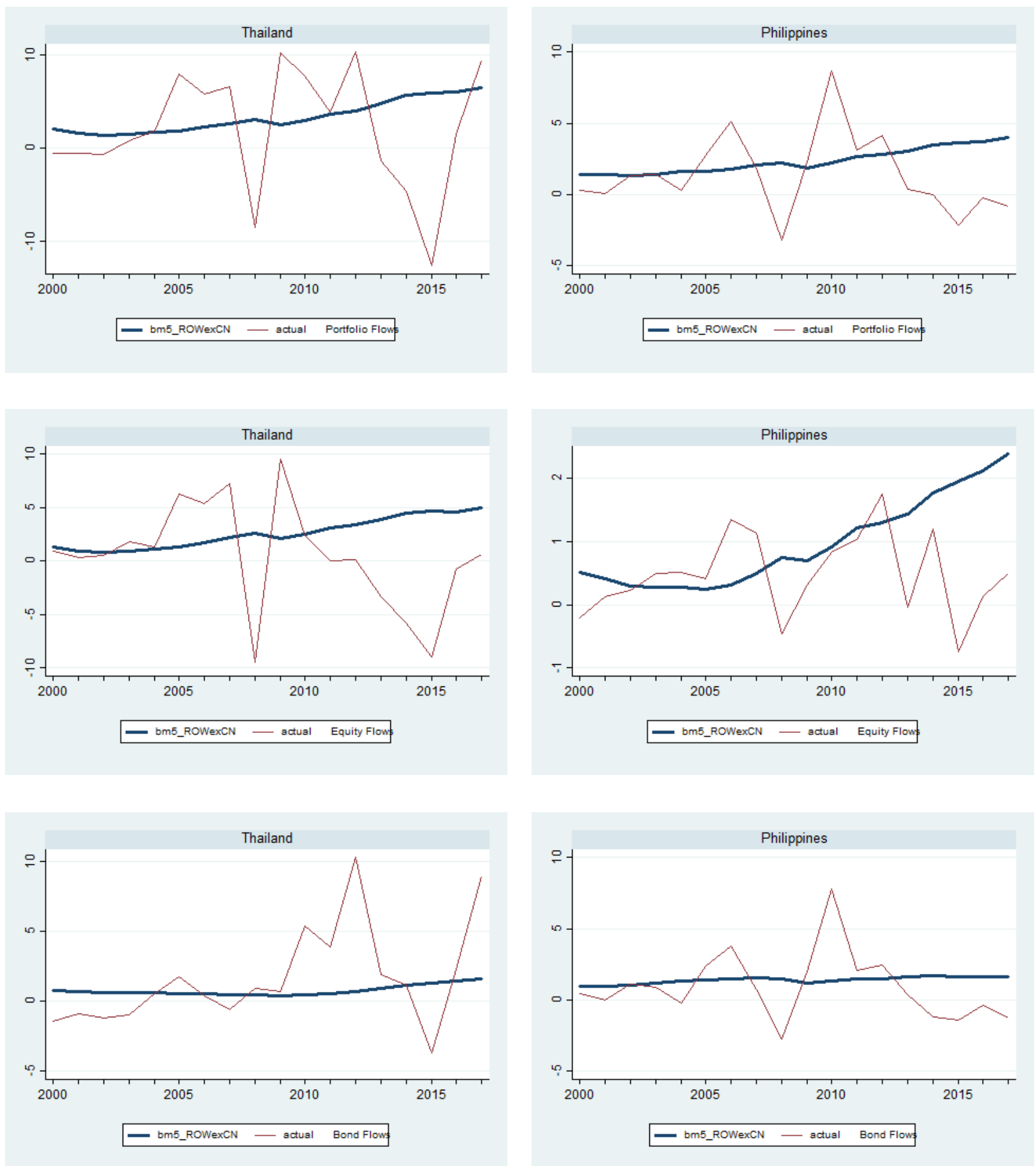


\section{d. Other EMEs}
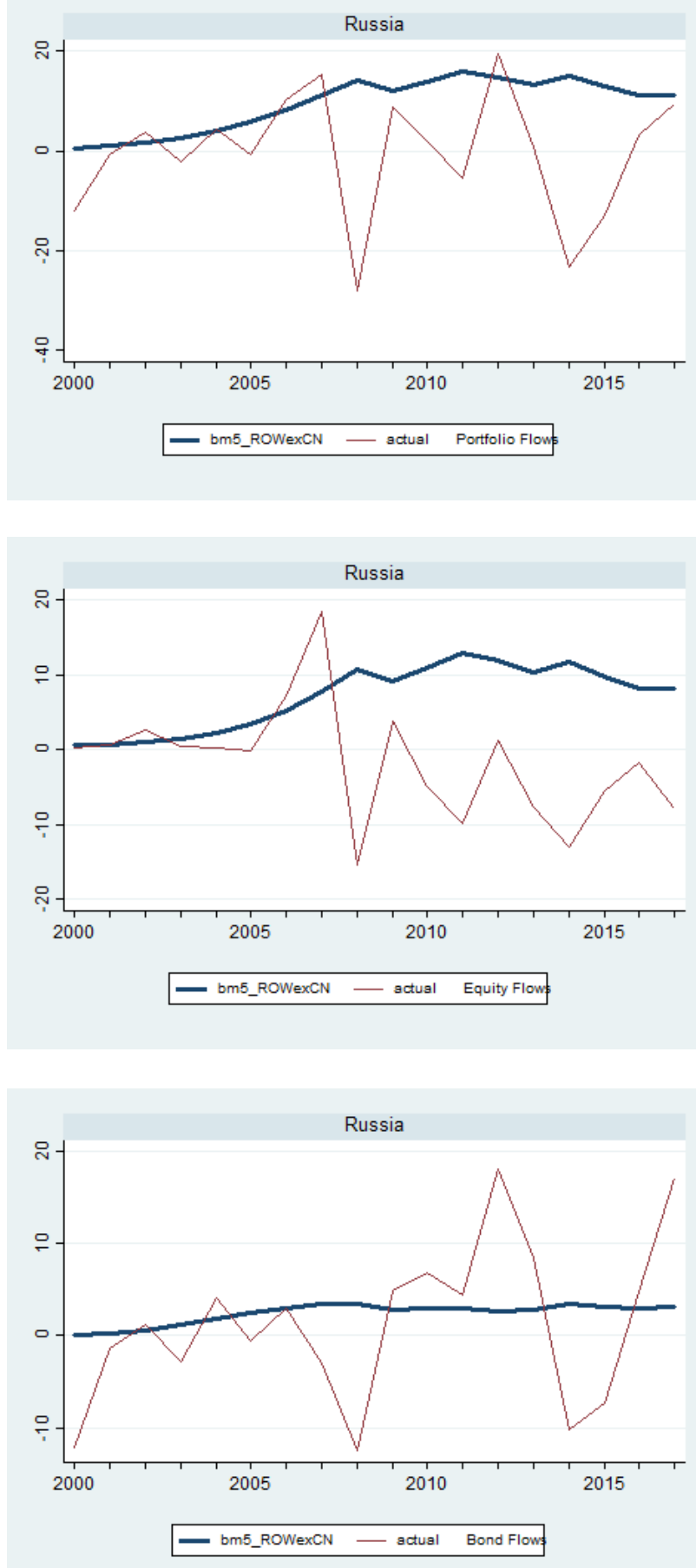
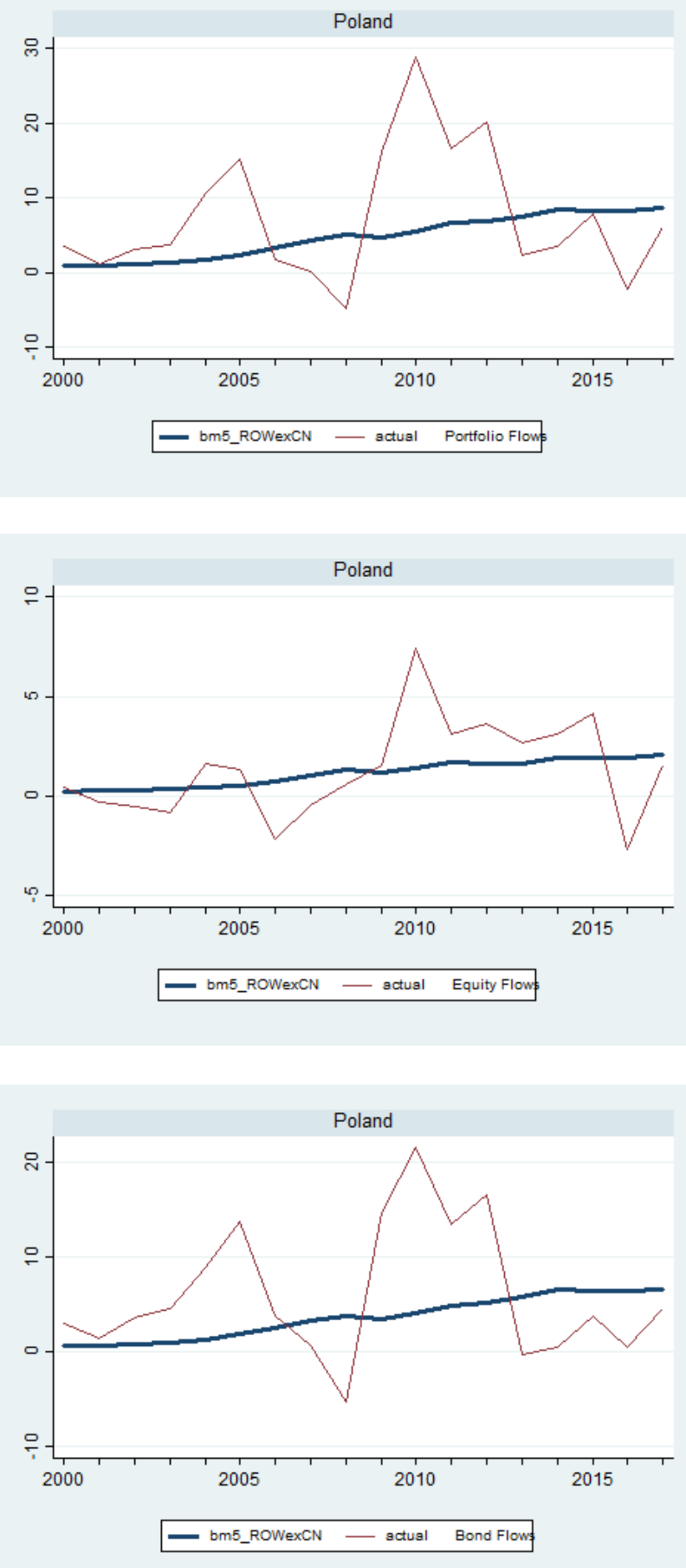

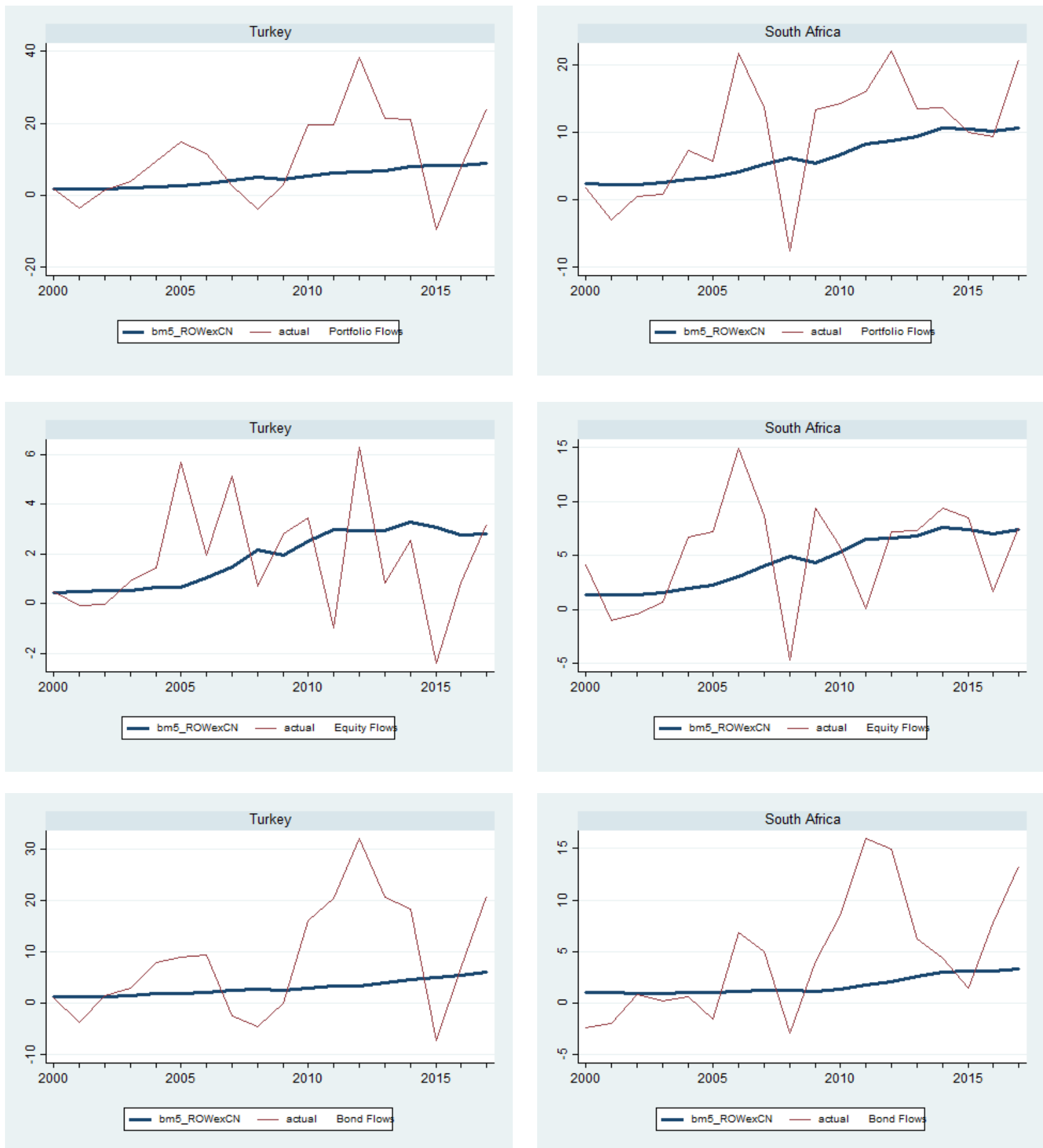